\title{
Calcite Twins, a Tool for Tectonic Studies in Thrust Belts and Stable Orogenic Forelands
}

\author{
O. Lacombe ${ }^{1,2}$ \\ 1 UPMC, Université Paris 6, UMR 7193, ISTEP, 75005 Paris - France \\ 2 CNRS, UMR 7193, ISTEP, 75005 Paris - France \\ e-mail: olivier.lacombe@upmc.fr
}

\begin{abstract}
Résumé - Les macles de la calcite, un outil pour les études tectoniques dans les chaînes plissées et les avant-pays peu déformés des orogènes - Les macles de la calcite sont utilisées depuis longtemps comme indicateurs de paléocontraintes et comme marqueurs de la déformation finie, en orientations comme en grandeurs. Au cours des 15 dernières années, des améliorations importantes des méthodes d'analyses existantes ont été réalisées et ont donné lieu à de nouvelles applications dans les chaînes plissées et les avant-pays peu déformés des orogènes. Cet article résume le principe des méthodes les plus utilisées en tectonique et illustre quelques apports de l'analyse des macles de la calcite pour la caractérisation non seulement des orientations et des grandeurs des paléocontraintes et de la déformation finie, mais également dans une certaine mesure de la paléotempérature et du paléoenfouissement. Cette revue se fonde en grande partie sur les études régionales que j'ai effectuées dans des contextes géologiques variés, comme les avant-pays des chaînes de Taiwan, des Pyrénées, du Zagros, des Rocheuses et des Albanides. Cet article discutera également la contribution de l'étude des macles de la calcite à la compréhension de la transmission des contraintes orogéniques en domaine intraplaque.
\end{abstract}

\footnotetext{
Abstract - Calcite Twins, a Tool for Tectonic Studies in Thrust Belts and Stable Orogenic Forelands - Calcite twins have been used for a long time as indicators of stress/strain orientations and magnitudes. Recent developments during the last 15 years point toward significant improvements of existing techniques as well as new applications of calcite twin analysis in thrust belts and forelands. This paper summarizes the principles of the most common techniques in this tectonic field and illustrates some aspects of the use of calcite twins to constrain not only stress/strain orientations and magnitudes, but also to some extent paleotemperature or paleoburial in orogenic forelands. This review is based in a large part on the studies that I conducted in various geological settings such as the forelands of Taiwan, Pyrenees, Zagros, Rockies and Albanides orogens. The contribution of calcite twin analysis to the understanding of the intraplate stress transmission away from plate boundaries is also emphasized.
} 


\section{INTRODUCTION}

In the upper part of the crust, the porous carbonate cover rocks constitute one of the main types of potential hydrocarbon reservoirs. The best exploitation of these hydrocarbons requires some important parameters to be known, including porosity and deformation of the rock material, from the grain scale to the fold scale and even to the basin scale. More particularly, the geometry and amount of deformation, the paleo-states of stress sustained by rocks, the way these parameters evolve with increasing depth, and the possibility for their extrapolation away from drill holes within the basin, must be carefully evaluated. To this respect the analysis of calcite twins is a useful tool to define precisely the mechanical behavior of the material and to describe stress and strain at depth.

E-twinning widespreadly occurs in calcite aggregates deformed at low pressure and temperature. Calcite twins have been considered for a long time as common stress/strain markers, and their analyses have been widely used to constrain the structural and kinematic evolution of orogenic forelands, e.g., Sevier and Appalachian forelands: Craddock and Van der Pluijm (1999); Northern Pyrenean foreland: Tourneret and Laurent (1990), Rocher et al. (2000); Southern Pyrenean foreland: Gonzales-Casado and Garcia-Cuevas (1999), Holl and Anastasio (1995); Subalpine chain: Ferrill and Groshong (1993); Taiwan: Lacombe et al. (1993, 1996a), Rocher et al. (1996), Hung and Kuo (1999); Hudson valley fold-thrust belt: Harris and Van der Pluijm (1998); Zagros: Lacombe et al. (2007). These studies have led to regionally significant reconstructions of tectonic stress and strain patterns, and, in few cases, to the quantification of differential stresses associated with folding and thrusting.
Calcite twins have also been used to decipher the (often polyphase) tectonic history of sedimentary basins, including successive extensional and compressional stress regimes as in the south Aquitaine basin (Rocher et al., 2000), the southern Rhinegraben (Larroque and Laurent, 1988), or the Paris basin (Lacombe et al., 1990, 1994; Rocher et al., 2004), among others.

This paper does not intend at providing a detailed review of the geometry and appearance of calcite twins; the reader can refer to the paper by Burkhard (1993). In the same way, it does not intend at covering the wide range of tectonic settings where calcite twin studies have been carried out. Although this methodology obviously also applies to extensional settings (including passive margins and extensional/transtensional basins), I selected hereinafter only several case studies, a large part of those being issued from my own works in the last 15 years, to illustrate the use of calcite twins and the main contributions of their analysis to the knowledge of thrust belts and their (stable) forelands, which are still important targets for oil/gas prospection. To this respect, I illustrate some aspects of the workflow of tectonic studies based on calcite twins. As Figure 1 shows, calcite twins studies can be fruitfully combined with analysis of fractures and fault slip data to unravel the paleostress and kinematic history of orogenic forelands; such analyses are carried out in the field or from oriented cores to derive stress-strain history, and potentially paleotemperature and paleoburial at the time of twin strain acquisition. Experiments help calibrating the critical resolved shear stress for twinning or documenting the reliability of calcite twins as paleothermometers or paleopiezometers. These data can be further used, together with geometrical constraints from seismic and wells, in kinematic, mechanical or fluid flow modelling of thrust belts and basins.

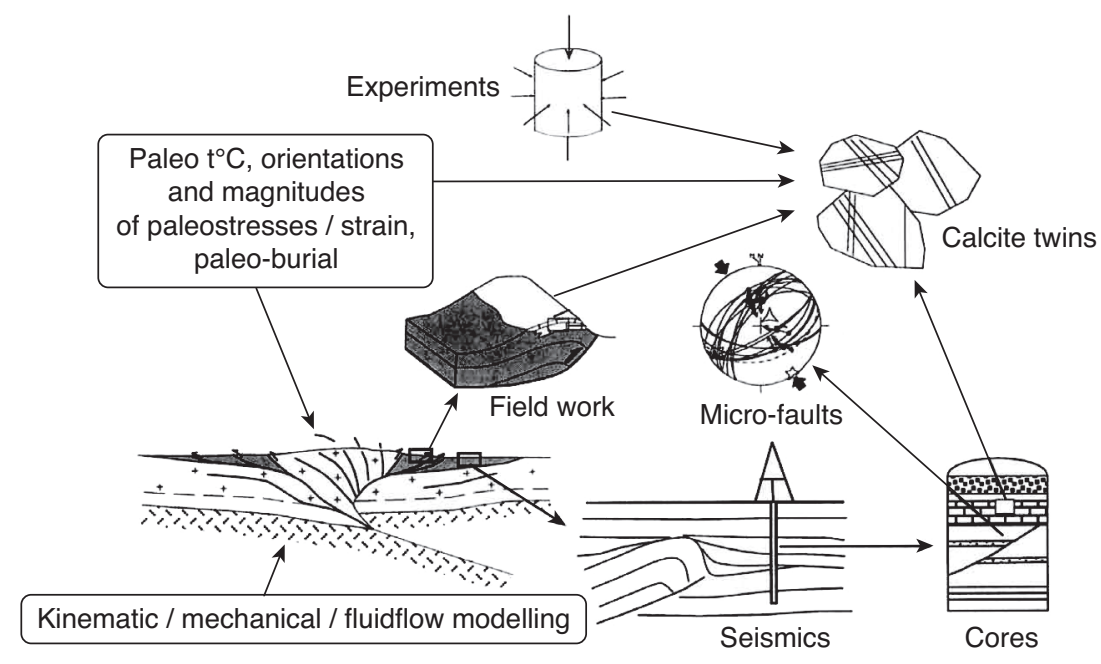

Figure 1

Principle of calcite twin analysis in the framework of the study of orogenic forelands. 


\section{GEOMETRY OF CALCITE TWINNING}

$E$-twinning is the dominant crystal-plastic deformation mechanism in calcite deformed below $400^{\circ} \mathrm{C}$. E-twinning occurs with a change of form of part of the host crystal by an approximation to simple shear in a particular sense and direction along specific crystallographic $e$-planes $\{01 \overline{1} 2\}$. The amount of "simple shear" is fixed and imposed by crystallography. The $\mathrm{C}$ axis being vertical, the sense of shear is such that the upper part of the crystal moves upwards, toward the $\mathrm{C}$ axis, like a reverse microfault. The resulting twinned portion of the crystal bears a mirrored crystallographic orientation to the untwinned portion across the twin plane (Fig. 2a). In contrast, twinning in dolomite mainly occurs along the $f$

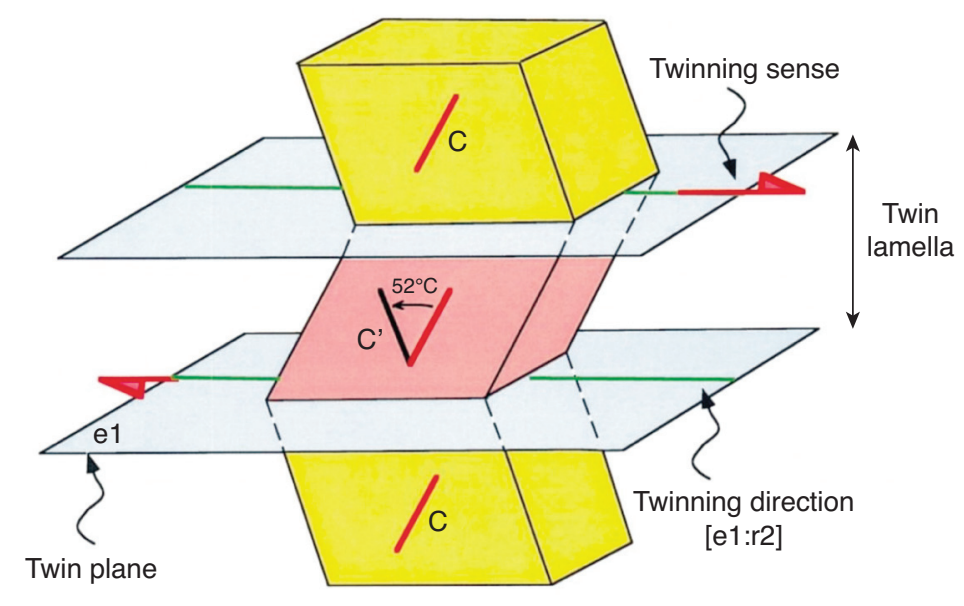

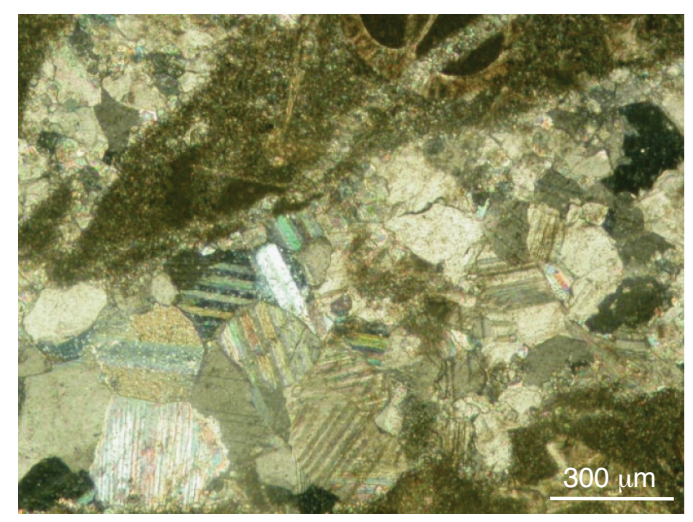

c)

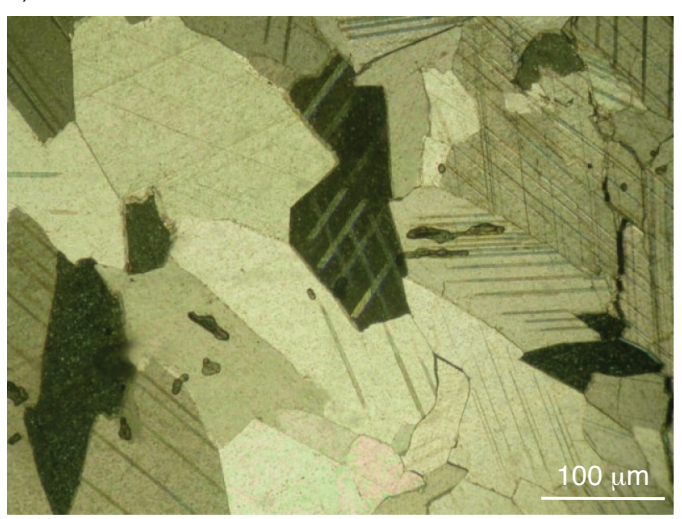

d)

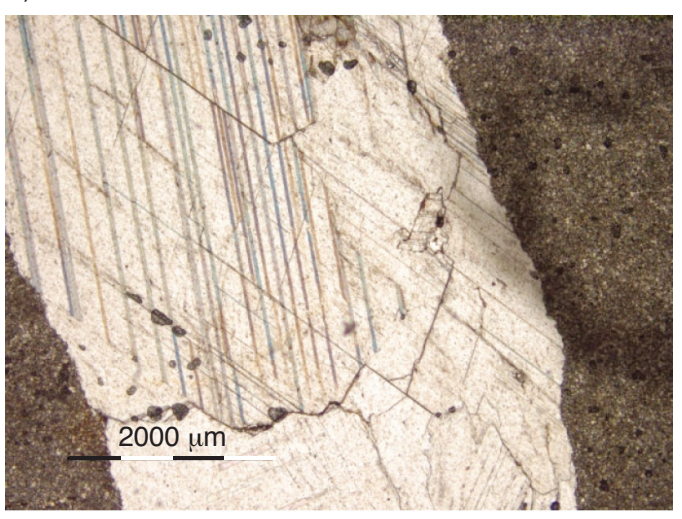

e)

Figure 2

a) Geometry of calcite twinning. C and C' refer to the optical axes of the host and twinned portion of the crystal, respectively (modified after Lacombe et al., 1990). The sense of shear is such that the "upper part" of the crystal moves toward the C axis like a "reverse microfault". B-E) Photographs of calcite material twinned in a thin twinning regime. b) Microphotograph of a Jurassic oolitic limestone from the Paris basin. c, d) Microphotographs from veins within Neogene limestones of the Zagros belt (courtesy of K. Amrouch). e) Microphotograph from a vein within Carboniferous limestones (Madison Fm, Wyoming, USA). 
planes $\{2021\}$, and is such that the optical axis being vertical, the upper part of the crystal moves downward, like a normal microfault.

Calcite twins are easily recognized under an optic microscope equipped with a 3-axis U-stage and can undoubtedly been distinguished from $r$-cleavage planes $\{10 \overline{1} 1\}$ by simply measuring the angle between the pole of the twin plane and the c-axis which is $26^{\circ}$ for $e$-twinning (instead of $44^{\circ}$ for $r$ gliding). So-called thin twins $(<1 \mu \mathrm{m})$ appear as thin black lines when viewed parallel to the twin plane (Fig. 2b-d). Thick twins $(>5 \mu \mathrm{m})$ viewed in the same way have a microscopically visible width of twinned material between black lines.

\section{CALCITE TWINS: A LOW-TEMPERATURE GEOTHERMOMETER}

Calcite $e$-twin width and morphology have been correlated with temperature of deformation in naturally deformed coarse-grained calcite (Ferrill, 1991, 1998; Burkhard, 1993; Ferrill et al., 2004). Ferrill et al. (2004) have compiled and analysed twin data from limestones of the frontal Alps (France and Switzerland) and the Appalachian Valley and Ridge and Plateau provinces (eastern United States) to document this temperature dependence. Mean calcite twin width has been found to correlate directly with temperature of deformation such that thin twins dominate below $170^{\circ} \mathrm{C}$ and thick twins dominate above $200^{\circ} \mathrm{C}$ (Fig. 3). Above $250^{\circ} \mathrm{C}$ dynamic recrystallization is an important deformation mechanism in calcite. Mean twin density (number of twins/mm)

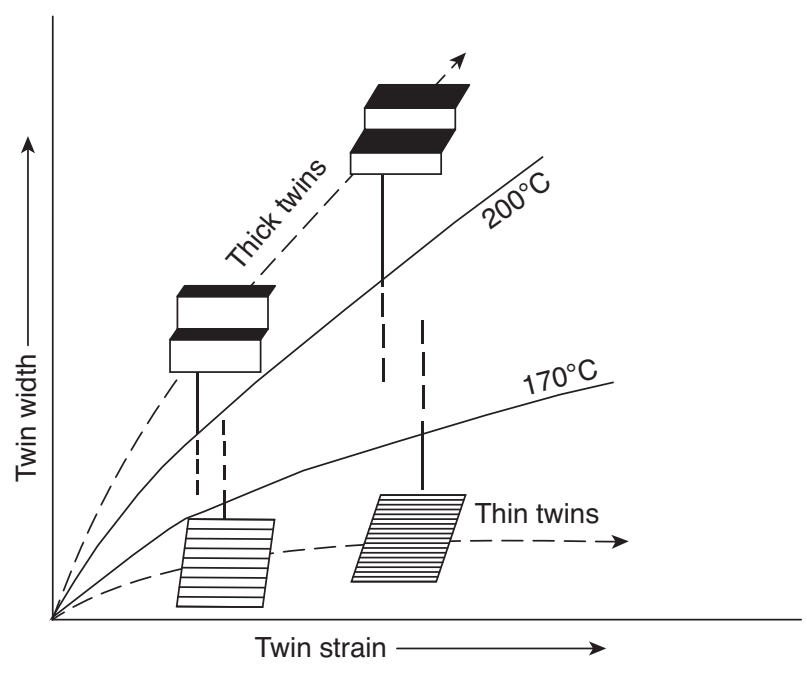

Figure 3

Twin strain $v s$ twin width plot illustrating the temperature dependence of twin geometry that may be used as a low temperature paleothermometer. Modified after Ferrill (1998). correlates negatively with temperature, and a cross plot of twin density with twin width can yield information about both strain and temperature of deformation (Ferrill et al., 2004). These relationships provide a quick and easy-to-use deformation geothermometer for rocks that might otherwise yield little or no paleotemperature data (Fig. 3).

A contradictory study has been however reported by Janssen et al. (2007). Their new field data show that twin morphology and twin width do not correspond to deformation temperatures at least for temperatures below $250^{\circ} \mathrm{C}$, and that deformation temperatures that are derived from twin width and twin morphology are not in agreement with temperatures estimated by other methods (e.g. vitrinite reflection, conodont color alteration index). The data from deformation experiments indicate that the width of calcite twin lamellae does change as a function of deformation temperature, but this change is not systematic and does not allow using calcite twins as a reliable low-temperature deformation geothermometer.

To summarize, the morphology of calcite twins, especially the occurrence of thin twins, is to a first-order an indicator of low temperature of deformation, below $170^{\circ} \mathrm{C}-200^{\circ} \mathrm{C}$, although its use as an accurate paleothermometer remains still a matter of discussion.

\section{CALCITE TWINS AS INDICATORS OF PALEO-STRESS ORIENTATIONS}

\subsection{The Calcite Stress Inversion Technique}

Since the pioneering work of Turner (1953), several methods of stress analysis have been developed on the basis of calcite twin data (Spang, 1972; Jamison and Spang, 1976; Laurent et al., 1981, 1984, 1990; Etchecopar, 1984; Pfiffner and Burkhard, 1987; Sperner and Ratschbacher, 1994; Nemcok et al., 1999).

Methods of stress analysis based on calcite twins share the fundamental assumption that the measured twins formed in a homogeneous stress field and were not passively rotated after formation. These methods are best applied to very small strains that can be approximated by coaxial conditions (Burkhard, 1993); in this case, the orientation of small twinning strain can be reliably correlated with paleostress orientation. In addition, the $e$-twinning in calcite is not thermally activated and is not sensitive to either strain rate or confining pressure; Spiers (1979) has further shown that deformation is distributed inhomogeneously between grains while the stress is much more homogeneous at the scale of the agregate. Calcite twinning therefore fulfills most requirements for paleopiezometry.

In contrast to Turner's (1953) technique which only applies when the stress ellipsoid is uniaxial and only yields orientations of the maximum and minimum principal stresses 
$\sigma_{1}$ and $\sigma_{3}$, and to the technique of Jamison and Spang (1976) which only provides values of maximum differential stress $\left(\sigma_{1}-\sigma_{3}\right)$ without any information on stress orientations and relative stress magnitudes (see Sect. 5.1.1), the computerized inversion of calcite twin data (Calcite Stress Inversion Technique, CSIT: Etchecopar, 1984; Laurent, 1984), provides five parameters among the six of the complete stress tensor. It is to date the only technique which allows simultaneous calculation of principal stress orientations and differential stress magnitudes from a set of twin data, and which therefore allows to relate unambiguously differential stress magnitudes to a given stress orientation and stress regime.

The CSIT assumes homogeneous state of stress at the grain scale and constant critical resolved shear stress for twinning $\tau_{a}$. The inversion process is very similar to that used for fault slip data (Etchecopar, 1984), since twin gliding along the twinning direction within the twin plane is geometrically comparable to slip along a slickenside lineation within a fault plane (Fig. 4). But the inversion process additionally takes into account both the twin planes oriented so that the resolved shear stress $\tau_{s}$ (the component of the shear stress along the twinning direction) was greater than $\tau_{a}$ (i.e., effectively twinned planes), and the twin planes oriented so that $\tau_{s}$ was lower than $\tau_{a}$ (i.e., untwinned planes) (Fig. 4). The inverse problem thus consists of finding the stress tensor that best fits the distribution of measured twinned and untwinned planes. This tensor must theoretically meet the major require-

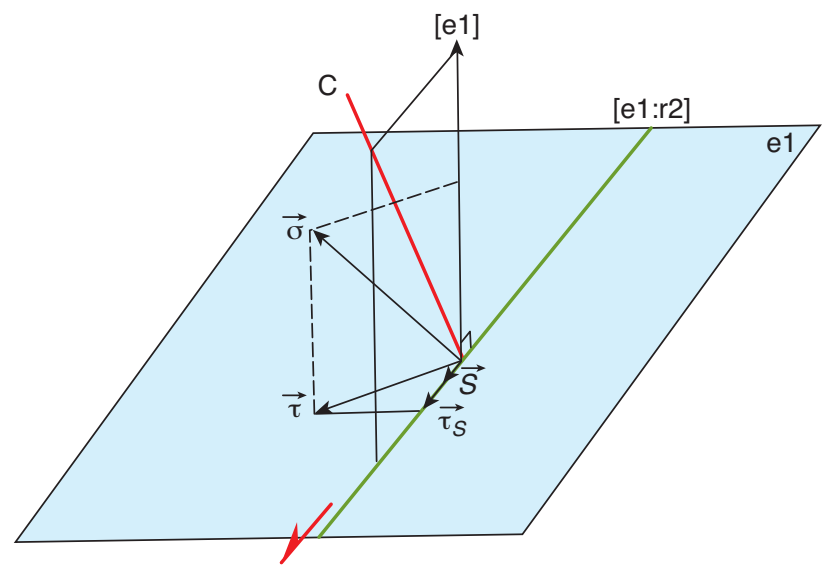

Figure 4

Principe of the analysis of calcite twins in term of stress. The inversion process is very similar to that used for fault slip data since twin gliding along the twinning direction within the twin plane is geometrically comparable to slip along a slickenside lineation within a fault plane. For twinning to occur, the resolved shear stress $(\tau$, the component of the shear stress along the twinning direction [e1: r2]) must exceed the critical resolved shear stress $\tau_{a}$. The inversion process takes into account both the twinned planes oriented so that $\tau_{s}$ is greater than, or equal to, $\tau_{a}$, and the untwinned planes oriented so that $\tau_{s}$ is lower than $\tau_{a}$ (untwinned planes). The red arrow indicates the imposed sense of twinning. ment that all the twinned planes consistent with it should sustain a resolved shear stress $\tau_{s}$ larger than that exerted on all the untwinned planes.

The inversion of slip (gliding) data along twin planes leads only to four parameters of the complete stress tensor $\mathrm{T}$ (for the way the fifth parameter is calculated, see Sect. 5.1.3). These four parameters, that define the reduced stress tensor $\mathrm{T}$ ', are the orientations of the three principal stress axes and the stress ellipsoid shape ratio $\Phi\left[\Phi=\left(\sigma_{2}-\sigma_{3}\right) /\left(\sigma_{1}-\sigma_{3}\right)\right]$. $\mathrm{T}^{\prime}$ is such that the complete stress tensor T is a function of T': $\mathrm{T}=k \mathrm{~T}^{\prime}+l \mathbf{I}$, where $k$ and $l$ are scalars $\left(k=\left(\sigma_{1}-\sigma_{3}\right)>0 ; l=\sigma_{3}\right)$ and $\mathbf{I}$ the unit matrix. The stress tensor solution is consequently searched as a reduced stress tensor T' and, in addition, the maximum differential stress $\left(\sigma_{1}-\sigma_{3}\right)$ is scaled to 1 (Etchecopar, 1984). For this normalized tensor the resolved shear stress $\tau_{s}$ acting along any twin plane therefore varies between -0.5 and 0.5 .

The first step of the inversion consists of obtaining a solution by applying a number of random tensors. For each tensor the stress components are calculated for all the twinned and the untwinned planes. However, because the resolved shear stress $\tau_{s}$ exerted on some untwinned planes may in practice be greater than that exerted along some twinned planes compatible with the tensor, the second step of the process consists of minimizing the function, $f$, ideally equal to 0 , defined as:

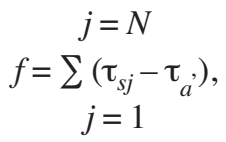

where $\tau_{a}$, is the smallest resolved shear stress applied on the twinned planes compatible with the tensor, and $\tau_{s j}$ are the resolved shear stresses applied on the $N$ untwinned planes $j$ such that $\tau_{s j}>\tau_{a}$, (for more details, see Etchecopar, 1984). The $\tau_{a}$, value is deduced from the inversion and corresponds to the critical resolved shear stress for the normalized tensor used for calculation. The optimization process leads to the reduced stress tensor solution that includes the largest number of twinned planes and simultaneously corresponds to the smallest value of $f$. The orientations of the three principal stresses $\sigma_{1}, \sigma_{2}$, and $\sigma_{3}\left(\sigma_{1} \geq \sigma_{2} \geq \sigma_{3}\right.$, compression being positive) are calculated, as well as the value of the stress ellipsoid shape ratio $\Phi\left[\Phi=\left(\sigma_{2}-\sigma_{3}\right) /\left(\sigma_{1}-\sigma_{3}\right), 0 \leq \phi \leq 1\right]$ that indicates the magnitude of $\sigma_{2}$ relative to $\sigma_{1}$ and $\sigma_{3}$. Application of the CSIT to experimentally deformed samples (Lacombe and Laurent, 1996; Laurent et al., 2000) shows that principal stress orientations are commonly calculated with uncertainties of $\sim 10-15^{\circ}$.

If more than $\sim 30 \%$ twinned planes in a sample are not explained by a unique stress tensor, the inversion process is repeated with the uncorrelated twinned planes and the whole set of untwinned planes. Where polyphase deformation has occurred, this process provides an efficient way of separating superimposed twinning events. Despite some limitations 
(Gagala et al., 2009), the potential of the CSIT to derive regionally significant stress patterns even in polyphase tectonics settings has been convincingly demonstrated by numerous studies (e.g., Lacombe et al., 1990, 1992; Lacombe, 2007; Rocher et al., 1996, 2000; and references therein).

\subsection{How to Obtain a Relative Chronology Between Calcite Twinning Events?}

Relative chronology between calcite twinning events is difficult to establish directly. Cross-cutting or offset relationships between twin lamellae from different sets in a grain can be observed using an electron microscope (e.g., Barber and Wenk, 1976), but such observations cannot be done optically simply using a U-stage. Only in some few particular cases can such geometrical relationships be observed optically (Fig. 5a), and such isolated observations are useless for establishing with certainty a relative chronology. Indeed, as for fault slip data for instance, extrapolating individual chronological observations between twin sets to a chronology of successive twinning events and related tectonic stresses would require a large number of consistent observations to be statistically representative, which are generally out of reach.

A relative chronology between different twin sets related to successive distinct tectonic stresses can however be sometimes established indirectly: for instance, when twin data are collected from both rock matrix and recognized vein sets, the chronology of twinning events and related stress/strain tensors can be constrained by comparing calcite twinning strain preserved in matrix (which presumably recorded the entire twinning history, at least the earliest stages since calcite may harden once twinned) and in the different vein sets.

Sampling in fold limbs also constrains the chronology of twinning relative to folding. One might expect that if a twin set formed during the initial phase of layer-parallel shortening and was subsequently tilted with the strata during folding, then one axis of the stress/strain tensor should be perpendicular

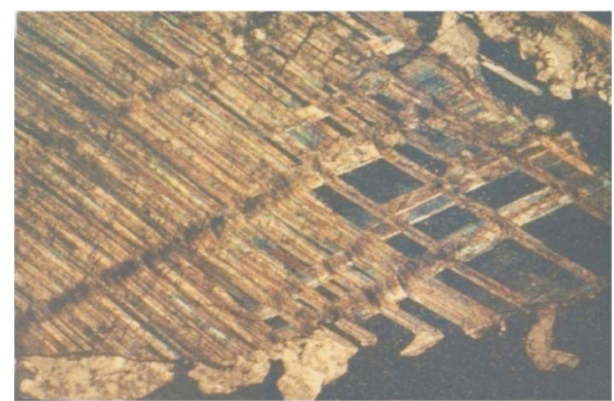

a)

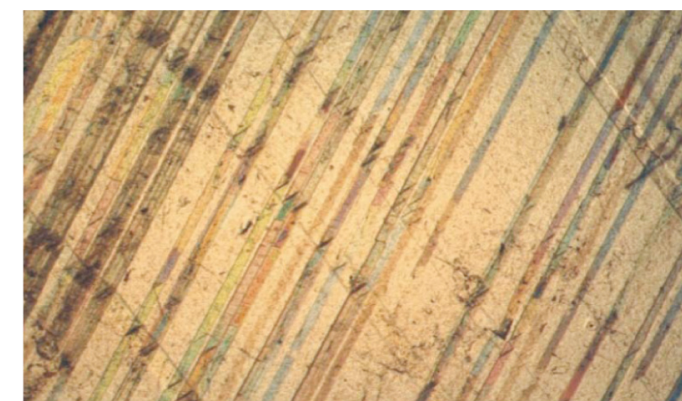

$\sigma_{1}: 275^{\circ}-78^{\circ}$

$\sigma_{2}: 168^{\circ}-03^{\circ}$

$$
\sigma_{3}: 078^{\circ}-11^{\circ}
$$$$
\Phi=0.68
$$

Tensor 1:

Extensional (strike-slip) stress regime

$$
\begin{gathered}
\sigma_{1}: 276^{\circ}-04^{\circ} \\
\sigma_{2}: 158^{\circ}-82^{\circ} \\
\sigma_{3}: 007^{\circ}-07^{\circ} \\
\Phi=0.80
\end{gathered}
$$

Strike-slip (extensional) stress regime

Figure 5

\section{b)}

$\mathrm{N}-\mathrm{S}$ trending vertical vein
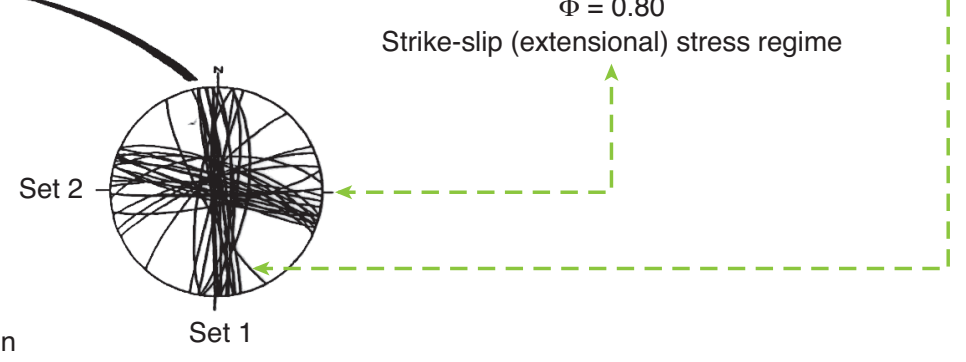

a) Examples of chronological relationships between twin lamellae observed with the U-stage (Lacombe, 1992). b) Example of the way a relative chronology may be established based on considerations of orientations of computed stress axes and vein orientations (Lacombe, 1992). The stress tensor determined from the calcite grains filling the $\mathrm{N}-\mathrm{S}$ trending vein displays a nearly $\mathrm{E}-\mathrm{W}$ trending $\sigma_{3}$ axis perpendicular to the vein strike, likely related to the vein formation; the other tensor (with stress axes unconsistent with the vein geometry) reflects a later, post-opening stress regime (see text for details) consistent with opening of E-W trending veins (set 2). 
to bedding and the other two would lie within the bedding plane. In contrast, late or postfolding twin sets should yield two horizontal stress/strain axes and one vertical one (assuming that the regional stress/strain field is in that orientation).

The way a relative chronology between successive twinning strains/stresses can be established through consideration of orientation of computed stress/strain axes with respect to vein orientation is shown in Figure 5b. It is based on the fact that a stress tensor determined from the calcite grains filling a vein with a $\sigma_{3}$ axis perpendicular to the vein strike is likely related to the vein formation while other tensors with stress axes unconsistent with the vein geometry reflect later, postopening stress regimes. Two sets of crosscutting subvertical veins, trending respectively $\mathrm{N}-\mathrm{S}$ and $\mathrm{E}-\mathrm{W}$, were observed in Ardèche (France) (Fig. 5b). The E-W set postdates the N-S one. Calcite twin analysis was carried out on the calcite grains filling a vein of the N-S set. Two stress tensors were obtained: one is extensional with a $\sigma_{3}$ axis perpendicular to the N-S vein but with a high $\Phi$ ratio (0.68) ("extensionalstrike-slip" regime), and another one, strike-slip in type, with $\sigma_{3}$ parallel to the N-S vein but perpendicular to the E-W trending veins and with also a high $\Phi$ ratio (0.8) ("strike slipextensional" regime) (Fig. 5b). A simple reasoning in that case suggests that the first tensor reflects the stress responsible for vein opening, therefore suggesting that the stress tensor with vein-parallel $\sigma_{3}$ was recorded later, thus yielding a relative chronology; this is in agreement with the relative chronology of veins observed at the mesoscopic scale (Lacombe, 1992).

This reasoning can be reasonably extended to a first approximation to stress tensors recorded by calcite filling veins by considering that the tensor consistent with vein opening was likely recorded during (or at the latest stage) of vein opening while other (unconsistent) tensors reflect later, post-opening stress regimes (e.g., Amrouch et al., 2010a).

To conclude, establishing a relative chronology based directly on twin observations and measurements is to date unfortunately nearly impossible. Considerations of the attitude of computed stress/strain axes with respect to vein orientations or to bedding dip, or the study of calcite twins in both matrix and veins sometimes allow to indirectly establish a relative chronology. This chronology may however remain questionable (for instance if based on tilted stress axes only) in the absence of additional (micro)structural observations.

\subsection{Calcite Twins and Paleostress Reconstructions in Fold-and-Thrust Belts}

\subsubsection{Paleostress Reconstructions from Calcite Twins in the Taiwan Foothills}

Arc-continent collision is occurring in the Taiwan segment of the active convergent plate boundary between the Philippine
Sea plate and Eurasia (Ho, 1986). The Taiwan fold-thrust belt developed as a growing sedimentary wedge prograding onto the Chinese passive margin in response to the $\mathrm{N} 310^{\circ}$ relative convergence between the Philippine Sea Plate and Eurasia. An initial submarine accretionary stage occurred mainly around $5 \mathrm{Ma}$ coeval with the beginning of the flexural subsidence of the Eurasian lithosphere (Mouthereau et al., 2001). It was followed between 2 and 1 Ma by the filling of the foreland basin. The last stage began at around $1 \mathrm{Ma}$, and the outermost thrusts were activated at that time, incorporating within the wedge the syntectonic deposits of the foreland basin.

Paleostress/strain analyses based on calcite twins were performed in the western foreland of Taiwan and in the Coastal Range in order to define the orientation of the tectonic forces responsible for mountain building and to constrain both the tectonic mechanisms prevailing during the Quaternary and the kinematics of fold-thrust units (Lacombe et al., 1993, 1996a; Hung, 1994; Rocher et al., 1996; Lin and Lee, 1997; Hung and Kuo, 1999: Fig. 6).

Among the localities in the western Foothills where the orientations of the Plio-Pleistocene stresses were reconstructed are Central Taiwan (Chukou area) and SW Taiwan (Kaohsiung area). Neogene limestones mainly consist there of reef formations probably developed on structural highs raised by folding (e.g., Gong et al., 1996; Lacombe et al., 1997, 1999), on top of which decreasing clastic flow induced a local favorable paleoecological environment for reef building organisms.

The Pliocene Kungtien limestone crops out in the Chunglun anticline in the Chukou area (Fig. 6); it was probably buried by $1500 \mathrm{~m}$ to $2500 \mathrm{~m}$ of sediments as estimated by the thickness of the upper Pliocene and Pleistocene sediments in this area (Ho, 1986). Inversion of twin data from the matrix of these limestones yields three types of stress tensors. All the samples display polyphase twinning strain and provide at least two superimposed stress tensors that belong either to the same type or to different types. The first type (I) corresponds to an extensional regime; the computed $\sigma_{1}$ axis is vertical and $\sigma_{3}$ axis is horizontal and trends NE-SW; both axes lie within the steeply dipping bedding (Fig. 7a2). Some normal microfaults measured at the same place also reveal an extensional regime, with a NW-SE direction of extension (Fig. 7b) poorly consistent with the NE-SW extension derived from calcite twins. The second type (II) corresponds to a compressional regime; $\sigma_{1}$ axis is horizontal and trends NW-SE; $\sigma_{3}$ axis is vertical. Type III tensors display nearly horizontal $\sigma_{3}$ axes and a $\sigma_{1}$ axis inclined consistently less than, but in the same direction as bedding dip; the $\Phi$ ratios are low, below 0.3 (Lacombe, 2001) (Fig. 7a2). Types II tensors are in agreement with post-folding reverse and strike-slip stress regimes derived from fault slip data (Lacombe et al., 1996a).

Type I tensors have not been interpreted as extensionrelated although normal faults related to foreland flexure 


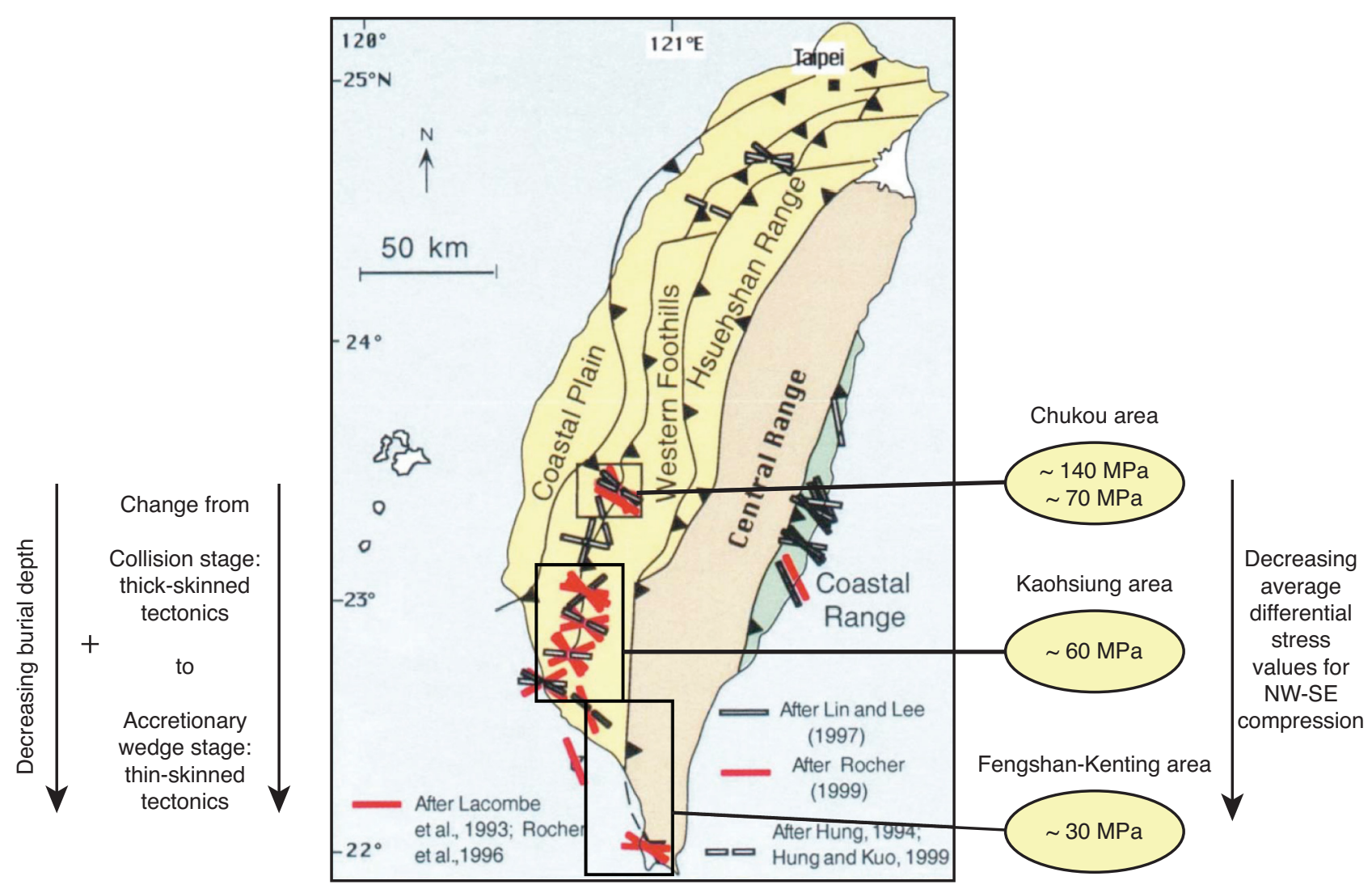

Figure 6

Plio-Quaternary stress orientations deduced from calcite twins within Neogene limestones in the Western Foothills and the Coastal Range of Taiwan. The frames show the areas investigated.

occur close to the mountain front (Fig. 7a). Instead, when these tensors (and that computed from fault slip data) are backtilted by rotation around the local bedding trend by the amount of bedding dip, a consistent NW-SE compression is obtained from both types of data (Fig. 7b). Type II and III tensors, as well as backtilted type I tensors therefore all display $\sigma_{1}$ axes highly oblique $\left(\mathrm{N} 110^{\circ}\right.$ to $\left.\mathrm{N} 160^{\circ}\right)$ to the $\mathrm{N} 020^{\circ} \mathrm{E}$ trending Chunglun fold axis, and are likely related to the regional compression. The geometrical relationships between stress axes and bedding support the interpretation of type II as post-folding tensors, while the type III probably corresponds to a twinning event contemporaneous with the latest stage of folding; type I tensors are interpreted as pre-folding (or early folding) stress tensors related to layer-parallel shortening (Lacombe et al., 1996a; Lacombe, 2001). Layer-parallel shortening preceding folding or occurring during the earliest stage of folding corresponds here either to a compressional stress regime or to a strike-slip stress regimes (twins) or to a compressional strike-slip stress regime with a low $\Phi$ ratio (faults). This result is in good agreement with what is commonly observed during layer-parallel shortening, with successive (or alternating) strike-slip and compressional stress regimes (see for instance Amrouch et al., 2010a for Sheep Mountain anticline (Sect.4.3), among others).

This study emphasizes that calcite twinning occurs mainly before (or during the earliest stage of) folding as layer-parallel shortening passively tilted during fold amplification (Craddock and Van der Pluijm, 1989; Ferrill and Groshong, 1993) and during the latest stage of (or after) fold development (Groshong et al., 1984; Rowe and Rutter, 1990), more rarely during folding. Limited evidence of synfolding twinning (type III tensors?) suggests that twinning strain is mainly achieved during two peaks of stresses which seem to predate immediately folding (buckling) and to prevail after fold tightening (Onasch, 1983). These results are in agreement with the work of Harris and van der Pluijm (1998) that show that twinning fabrics in the Hudson valley fold-thrust belt fall into two populations: a strain population initiated as a prefolding layer-parallel shortening strain that was subsequently modified to its present orientation by active grain scale rotation during flexural folding, and a second strain population that reflects post-folding superimposed 

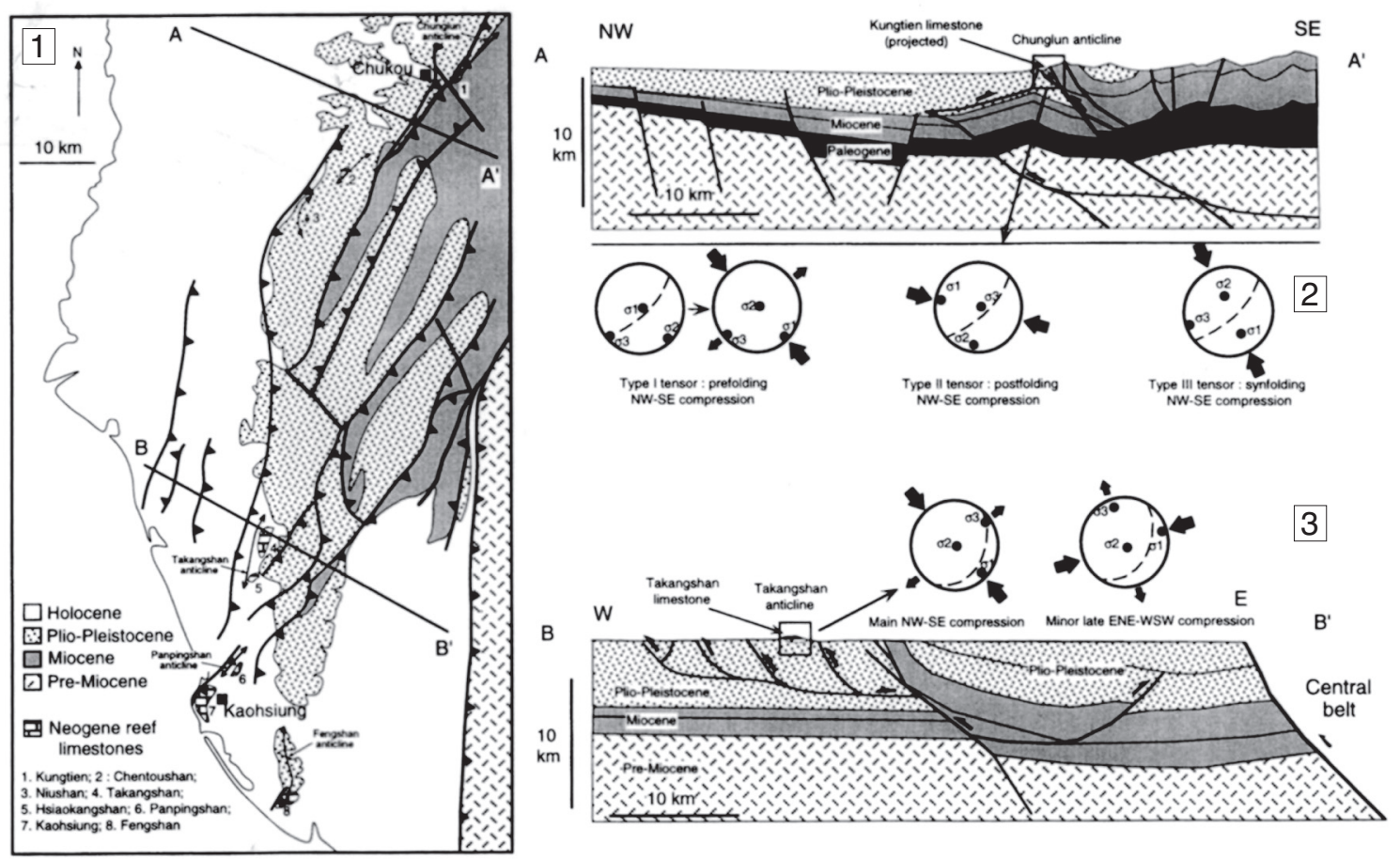

a)

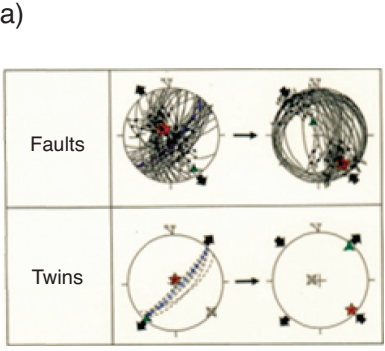

b)

Figure 7

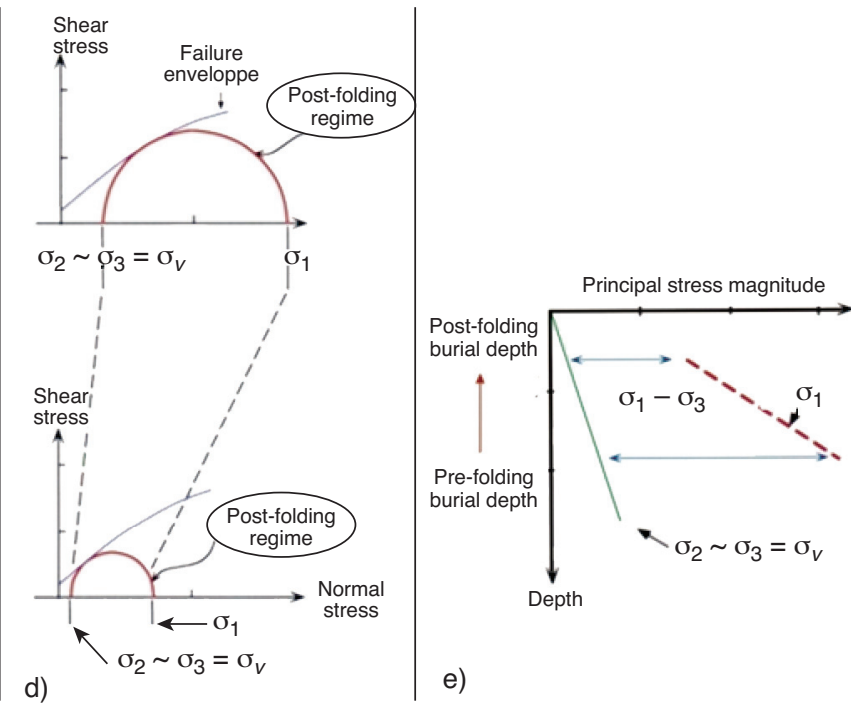

a1) Schematic structural map of SW Taiwan (location in Fig. 6, upper frame, Chukou area) showing the main thrust units and the outcropping formations. The limestone outcrops are labeled 1 to 8. a2) Balanced cross section in the Chukou area across the Chunglun anticline (Mouthereau et al., 2001) and types of stress tensors related to the NW-SE compression deduced from analysis of calcite twins. Bedding is shown on stereonets as a dashed line. The Kungtien limestone has been projected in the section. Note the involvement of the pre-Miocene formations and the superimposed shallow and deep-seated decollement tectonics. a3) Balanced cross section in the Kaohsiung area across the Takangshan anticline (Mouthereau et al., 2001) and stress tensors related to NW-SE and ENE-WSW compressions deduced from analysis of calcite twins. Note that most of deformation in the western part of the section occurs above a shallow decollement; b) Principle of backtilting of stress axes computed from faults and calcite twins (type I tensors). Diagrams illustrating fault-slip data: thin curves represent fault planes and dots with double arrows (left - or right - lateral) or simple ones (centripetal-reverse/centrigugal-reverse) indicate striations. Stress axes computed from fault slip data and calcite twin data shown as stars with five points $\left(\sigma_{1}\right.$, orange), four points $\left(\sigma_{2}\right)$ and three points $\left(\sigma_{3}\right.$, green). Bedding planes shown as dashed lines (average bedding in blue). Large black arrows: Direction of compression (convergent arrows) and extension (divergent arrows). After backtilting, faults and twins reveal a consistent NW-SE compression at high angle to fold axis; c) Simplified tectonic model of fault-related fold development and contemporaneous evolution of stress magnitudes based on the results from the Chunglun anticline; d) The principal stress values associated with the NW-SE compression in the Chunglun anticline are determined as follows: the Mohr circles whose diameters correspond to the average differential stress values deduced from inversion of calcite twin data for pre-folding and post-folding stress regimes are fitted with the failure curve determined from laboratory experiments (Lacombe et al., 1996a); this is justified since newly formed faults developed under both stress regimes (Lacombe and Laurent, 1992; Lacombe, 2001); e) Inferred evolution of stress magnitudes with depth. Note the decrease of differential and principal stress values related to synfolding erosion and subsequent exhumation. 
homogeneous strain, with no evidence of syn-folding twinning strain (see also discussion in Sect.4.3).

Despite the complexity of the Chunglun anticline, a relatively simple tectonic history can be drawn for the timespatial relationships between stresses inferred from twins and fault propagation folding (Fig. 7c). First, twinning strain occurs (type I tensors), before or immediately prior to folding (layer-parallel shortening); it corresponds to mixed (successive? alternating?) compressional and strike-slip stress regimes, under an average NW-SE compression. The travel along the ramp and the related transport is associated with shortening oblique to bedding that is accommodated mainly by bedding-parallel slip (and possibly in a minor part by twinning). Finally, because of locking of the thrust, the whole system is homogeneously shortened during a late stage of fold tightening (type II tensors) (Fig. 7c). The variations of differential stress magnitudes related to these different stages (Fig. 7d,e) will be discussed in a later section (Sect. 5.3.1).

In SW Taiwan, calcite twin analyses were carried out from Pleistocene limestones from Takangshan, Panpingshan and Fengshan anticlines (Lacombe et al., 1993, 1999) as well as in the Kenting platform in the Hengchun peninsula (Rocher et al., 1996). These limestones were never significantly buried (maximum burial depth of $300 \mathrm{~m}$ ). Two compressional stress regimes have been identified: a NW-SE compression, followed by a nearly E-W compression (Fig. 7a3). Both stress regimes were also identified from fault slip data (Lacombe et al., 1997, 1999). Unfortunately, the low bedding dip precludes any reliable chronological reasoning based on the attitude of computed stress axes with respect to folding. The NW-SE compression, trending nearly perpendicular to fold axes, is associated with the major stage of fold development (Lacombe et al., 1999). The nearly E-W compression mainly prevailed during the latest stages of, or after, folding; the ENE trend has been interpreted as a stress deviation of the E-W trend related to the incipient right lateral motion along NNE thrusts. This E-W compression, associated with a southward increasing component of N-S extension as revealed by fault slip data, can be correlated with the onset of the present-day tectonic escape in SW Taiwan (Lacombe et al., 2001).

\subsubsection{Paleostress Reconstructions from Calcite Twins in the Zagros Fold Belt}

The Zagros belt results from the collision between Arabia and Central Iran, beginning in Miocene times and continuing today (e.g. Stocklin, 1968) (Fig. 8a). The Zagros belt was built by folding of a 6-8 km thick Phanerozoic cover detached from the Precambrian basement by the $1-2 \mathrm{~km}$ thick early Cambrian Hormuz salt layer (Colman-Sadd, 1978). Earthquake focal depths (e.g., Talebian and Jackson, 2004), balanced cross sections (e.g., Blanc et al., 2003) and critical wedge modeling (Mouthereau et al., 2006) indicate that the basement is also likely involved in collisional shortening.
The late Neogene stress pattern was investigated across the Zagros belt and in the southern Iranian Plateau by carrying out a stress inversion of calcite twin data (Lacombe et al., 2007: Fig. 8b). Sampling was carried out mainly in the straight limbs of the major folds, in veins and host rocks. The sampled rocks are Late Cretaceous to Middle Miocene in age. Most veins in fold limbs are perpendicular to the bedding and have a strike either perpendicular or parallel to bedding strike; they likely formed coevally with fold growth during the Mio-Pliocene.

The predominant compressional trend is nearly constant throughout the Zagros Simply Folded Belt and the Southern Iranian Plateau: it is oriented $025^{\circ}\left( \pm 15^{\circ}\right)$, at high angle to the folds (Fig. 8b). In Andersonian terms, the stress regime is either truly compressional (vertical $\sigma_{3}$ axis) or strike-slip (vertical $\sigma_{2}$ axis), without any obvious regional variation in the results. The computed $\Phi$ ratios are often lower than $0.2-0.3$, indicating that the values of the principal stresses $\sigma_{2}$ and $\sigma_{3}$ were nearly similar, and hence that $\sigma_{2}$ and $\sigma_{3}$ axes could easily switch between being vertical and horizontal. Some samples also yield extensional stress tensors with nearly vertical $\sigma_{1}$ axes and nearly horizontal, NW-SE -trending $\sigma_{3}$ axis (Fig. 8b).

Inspection of the attitude of the stress axes with respect to bedding indicates that in both veins and host rocks, twinning recorded predominantly the stresses during late-stage fold tightening. Only few samples yield a pre-folding (or possibly a syn-folding) NE-directed compression (Lacombe et al., 2007). This study complements earlier work concerned with the relative timing of calcite twinning strain and fold belt development (e.g., Harris and Van der Pluijm, 1998; Lacombe, 2001), in that it emphasizes that twinning may record not just layer-parallel shortening as often stated or assumed (e.g., Craddock and Van der Pluijm, 1999), but also late fold tightening strain.

The $025^{\circ}$ compressional trend recorded by twinned calcite agrees well with the Neogene compressional trend revealed by inversion of fault slip data (Fig. $8 \mathrm{c}$ ) but also with the current compressional trend derived from inversion the focal mechanisms of basement (and of few cover) earthquakes (Lacombe et al., 2006, 2007). The compressional/strike-slip stress regime accounts for the kinematics of the major faults and for the combination of strike-slip and thrust-type focal mechanisms of earthquakes whatever their magnitudes and focal depths. The regional compression was therefore approximately constant in space (across the Zagros collision zone) and time (during the late Neogene). Long-term calcite twin data and short-term earthquake data indicate that in the Fars, the Arabia-Eurasia convergence has been accommodated by both across-strike shortening and strike-slip faulting throughout the cover and the basement, with an minor component of belt-parallel extension.

It is worth noting that the Hormuz decollement poorly decouples principal stress orientations in the cover and the 

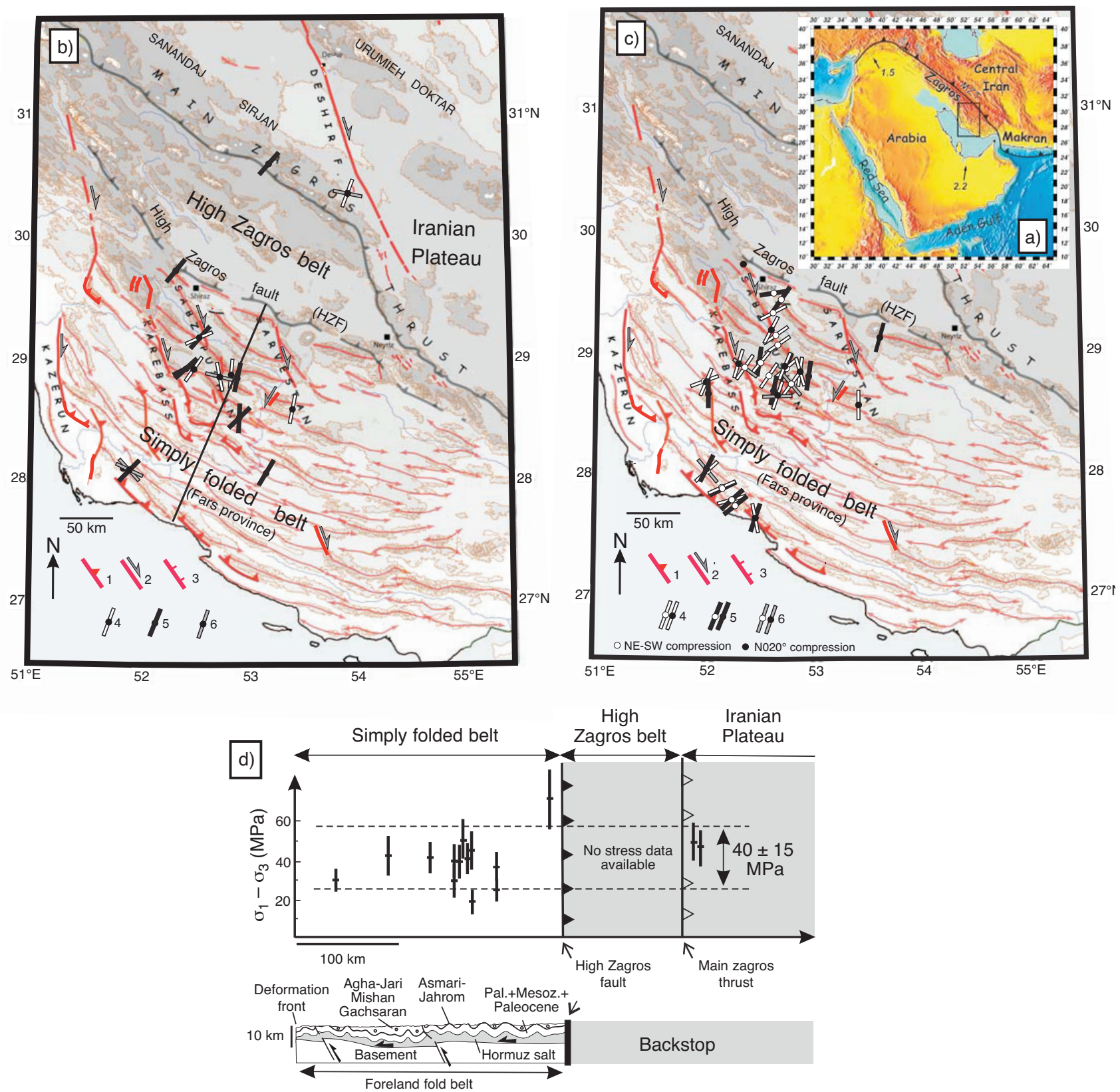

Figure 8

a) Geodynamic setting of the Arabia-Eurasia collision. GPS velocities in cm/yr (Vernant et al., 2004). b) Schematic structural map of the Fars with Neogene paleostress trends derived from calcite twin analysis (Lacombe et al., 2007). Topographic contours and shading every $500 \mathrm{~m}$. The main anticline axes are reported. 1: Thrust; 2: Strike-slip fault; 3: Normal fault; 4 and 5: Main compressional trend, strike-slip and reverse regimes, respectively; 6: Belt-parallel extensional trend. c) Neogene paleostress trends derived from fault slip analysis (Lacombe et al., 2006). 1 to 6: same key as in b). d) Schematic geological cross section across the Zagros Simply Folded Belt and differential stress magnitudes in the Simply Folded Belt and the southern Iranian Plateau (sites projected perpendicularly on transect of Fig. $8 b$ ). The heavy line with black triangles represents the active High Zagros fault; the line with white triangles represents the inactive Main Zagros Thrust (after Lacombe et al., 2007).

basement (Lacombe et al., 2007). The comparison of the stress field above and below the decollement of the still active Zagros belt therefore complements an earlier work in the Jura belt (Becker, 2000) and yields a potential analogue for ancient, salt-based fold belts.

\subsection{Paleostress Reconstruction from Calcite Twins in the Northern Pyrenean Foreland}

The map of Figure 9a summarizes the available paleostress trends reconstructed from calcite twins in the north Pyrenean 


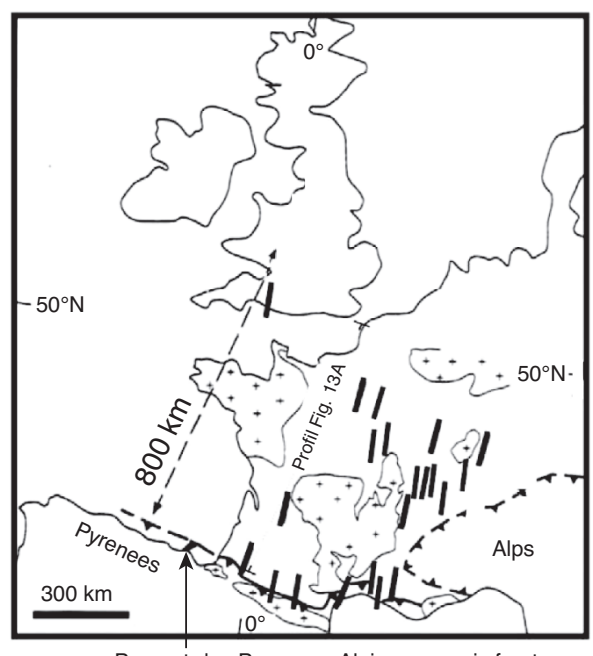

a)

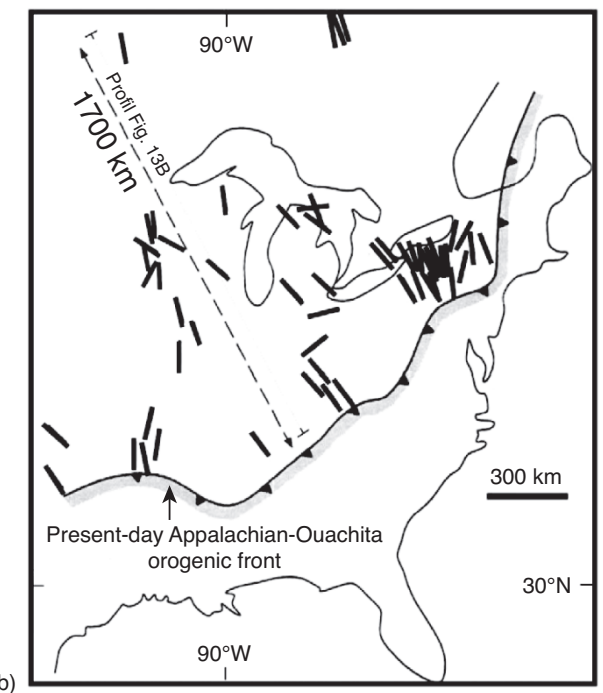

Figure 9

a) Pyrenean compressional trends derived from calcite twins in the north Pyrenean foreland (modified after Lacombe et al., 1996b).

b) Layer-parallel shortening trends preserved in twinned calcite in the Appalachian-Ouachita foreland (modified after Craddock et al., 1993).

foreland compiled by Lacombe et al. (1996b) and completed by data from the Lorraine platform and Wight island by Rocher et al. (2004). Most sites show a polyphase tectonic history with generally various paleostress trends, but in most cases one of the identified trends is oriented roughly $\mathrm{N}-\mathrm{S}$, i.e., perpendicular to the Pyrenean-Provence thrust front. This trend is identified in Mesozoic and Paleocene-Eocene formations, and when fault slip data are associated, they show that this N-S trend predates the E-W Oligocene extension and the WNW "alpine" compression, and is therefore undoubtedly related to the late Eocene Pyrenean tectonism (Lacombe et al., 1990). The record of N-S compressional trend up to $800 \mathrm{~km}$ away from the thrust front (Fig. 9a) supports far-field stress transmission from the Pyrenean front in the foreland. This has led Lacombe and Mouthereau (1999) to distinguish several fronts related to the Pyrenean orogeny: the front of the thrust belt, the reactivation front defined as the outermost structures reactivated during the Pyrenean orogeny and the deformation front corresponding to the outermost record by microstructures of the Pyrenean orogenic stresses (including layer-parallel shortening).

This far-field stress transmission (see also Sect. 5.5) is of first-order importance since calcite twinning related to layerparallel shortening is often associated with pressure-solution which reduces the porosity and therefore strongly controls porosity-permeability evolution in forelands (e.g., Roure et al., 2005); far-field horizontal tectonic stresses therefore contribute to this evolution in addition to mechanical and chemical compaction due to sediment burial and temperature.

\section{CALCITE TWINS AS INDICATORS OF PALEO-STRAIN ORIENTATIONS}

\subsection{The Calcite Strain Gauge Technique}

The Calcite Strain Gauge Technique CSGT (Groshong, 1972, 1974) allows computation of the strain ellipsoid. Strain magnitudes vary greatly, however, depending on factors such as lithology, grain size and porosity, and are a function of twin thickness. The results of Evans and Dunne (1991) and Groshong et al. (1984) demonstrated that the strain gauge gives quite accurate measurement of the orientations of the principal strain axes from 1 to $17 \%$.

The Groshong CSGT takes into account the widths of thin and thick twins. For each twin set measured, the average twin width, number of twins, grain width normal to twins, and the orientations of the $c$-axis and the $e$-twin plane are measured. In general, widths of thin and thick twins are measured separately.

The tensor shear strain for a given twin set in the plane defined by the normal to the $e$-twin plane and the glide direction $g$ [e1:r2] (i.e., the intersection between the $e$-twin plane and the $r\{10 \overline{1} 1\}$ cleavage plane) is given by:

$$
\Gamma_{e g}=\frac{1}{2} \tan \varphi=\frac{0.347}{w} \sum_{i=1}^{n} t_{i}
$$

where $\varphi$ is the angle of shear, $w$ is the thickness of the grain perpendicular to the twin plane, and:

$$
\sum_{i=1}^{n} t_{i}
$$



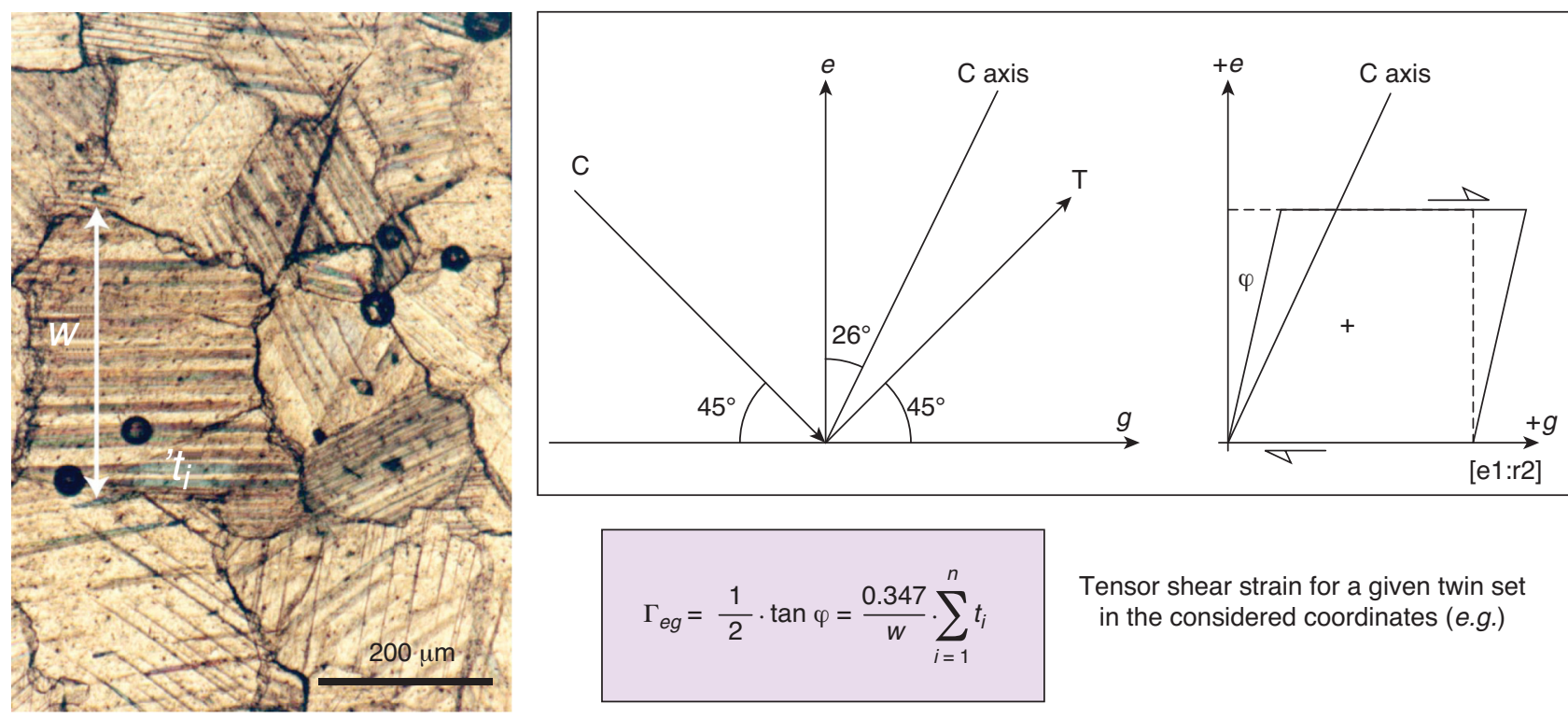

$\Gamma_{e g}=\left(l_{e} l_{g}-n_{e} n_{g}\right) \varepsilon_{x}+\left(m_{e} m_{g}-n_{e} n_{g}\right) \varepsilon_{y}+\left(l_{e} m_{g}+m_{e} l_{g}\right) \Gamma_{x y}+\left(m_{e} n_{g}+n_{e} m_{g}\right) \Gamma_{y z}+\left(n_{e} l_{g}+l_{e} n_{g}\right) \Gamma_{z x}$, where $\varepsilon_{x}$ and $\varepsilon_{y}$ are normal strains, $\Gamma_{y z}, \Gamma_{x y}$ and $\Gamma_{z x}$ are shear strains in a $(x, y, z)$ coordinate frame, and $l_{e}, m_{e}, n_{e}$ and $l_{g}, m_{g}, n_{g}$ the direction cosines of $e$ and $g$ in the $(x, y, z)$ coordinate frame. $\varepsilon_{z}=-\left(\varepsilon_{x}+\varepsilon_{y}\right)$ assuming no volume variation $(\Delta \mathrm{V}=0)$

Figure 10

Principle of Groshong's strain gauge technique. Geometry of Turner's optimal position for twinning, principle of calculation of the tensor shear strain for a given twin set and of the complete calcite strain tensor. $e$ is the normal to the twin plane, $g$ the direction of twinning [e1: r2], $\mathrm{C}$ and $\mathrm{T}$ are the Turner's compression and extension axes, respectively. See text for details.

is the total width of the twin lamellae in the set (Fig. 10). The data are treated like strain gauge measurements and a least squares solution is used to find the complete calcite strain tensor for the sample. Principal strain directions and magnitudes are determined using standard eigenvector and eigenvalue analysis. The principal strains are $\varepsilon_{\min }, \varepsilon_{\text {int }}$, and $\varepsilon_{\max }$, expressed in \% as + or - changes in length.

The CSGT not only determines a strain tensor from a twin data set, but also detects twins of incompatible orientations: positive and negative expected values (PEV and NEV, respectively) are computed for all twins in a given thin section. PEV and NEV correspond to twin sets with sense of shear consistent and unconsistent with the calculated strain tensor, respectively. A high percentage of NEV (40\%) results either from large non-coaxial deformation or from superimposition of a second, non-coaxial twinning event. NEV are either (usually) discarded as being noise, or used to run a new analysis. However, Groshong's technique only efficiently separates perpendicularly superimposed strain or, in practice, superimposed strain directions lying at more than $45^{\circ}$ (Teufel, 1980). So in many cases, superimposed twinning events cannot be detected. This is for instance illustrated in the Taiwan western foreland (Fig. 6) where polyphase tectonism is identified from inversion of calcite twin data and in most cases independently confirmed by fault slip analysis (e.g., Lacombe et al., 1993, 1999; Rocher et al., 1996), whereas it can only be suspected from highly inhomogeneous strain in the same area using Groshong's technique (Hung and Kuo, 1999).

A comparison of different techniques of stress/strain reconstructions can be found in the papers by Shelley (1992) and Burkhard (1993).

\subsection{Calcite Twinning Finite Strain Orientations in the Sevier/Appalachian Undeformed Forelands (USA)}

Craddock et al. (1993) collected Paleozoic limestones and dolomites that cover cratonic north America throughout the foreland of the Appalachian-Ouachita fold-and-thrust belt at distance up to $1700 \mathrm{~km}$ from the orogenic front, as well as from within the thrust belt. They also collected from five adjacent provinces to demonstrate the distinctiveness of the twinning strain preserved in the Appalachian-Ouachita foreland. All their samples indicate a simple coaxial deformation history based on low NEV percentages, and the presence of only one twin lamellae set in most grains. All the data have low $\varepsilon_{\min }$ shortening strain values $<6 \%$. The layer-parallel subhorizontal shortening strain fabric preserved in twinned calcite is present everywhere, is perpendicular to the orogenic 
fronts of the Appalachian and Ouachita mountains and is parallel to the thrust-transport direction (Fig. 9b). This fabric is thus likely related to the far-field transmission of orogenic stresses into the craton.

The layer-parallel shortening twinning strain is found in the same carbonates in both the allochtonous thrust belt and the autochtonous foreland. The authors concluded that the thrust-transport parallel strain is an early orogenic fabric that extends up to $1700 \mathrm{~km}$ from the margin of the present-day thrust belt (Fig. 9b), part of which were transported passively within the thrust sheets as the thrust belt developed. A similar analysis has been carried out by Craddock and van der Pluijm (1999) in the foreland of the Sevier-Laramide belt.

Together with the study of Pyrenean compressional trends in the northern Pyrenean foreland (Fig. 9a and Sect. 3.4), these studies clearly demonstrate the sensitivity of calcite twinning to small stress magnitudes (see also Sect. 5.5) and its potential as stress/strain indicator even in nearly undeformed forelands. Reported stress and strain patterns are remarkably homogeneous in terms of orientations. This suggests that regional-scale provinces of homogeneous paleostresses can be recognized, as regional-scale provinces of homogeneous contemporary stresses are identified on the World Stress Maps. The purpose of the successive compilations of the World Stress Map (e.g., Zoback et al., 1989; Zoback, 1992; Heidbach et al., 2008, 2010) was to evaluate the forces acting on the lithosphere and to investigate intraplate seismicity. Only indicators of the stress field at depth were considered while all the data which may be influenced by topography effects or by human activity were excluded. Stress data used for the compilation come from earthquake focal mechanisms, deep stress measurements, borehole breakout orientations, and sometimes results from microtectonic analysis. Most of the data were obtained on the assumption that the vertical direction is principal, the principal directions of the stress field being uniquely defined by the maximum horizontal principal stress orientation. The modern intraplate stress field is generally compressive (i.e., thrust or strike-slip faulting). Despite local stress sources such as density contrasts and active fault systems that may also exert a significant control on the regional stress pattern (short wavelength stress pattern $<200 \mathrm{~km}$ : Heidbach et al., 2010), the current intraplate stress field is characterized by remarkably uniform stress orientations and relative magnitudes over regions with dimensions larger than $2000 \mathrm{~km}$, and is probably primarily controlled by plate boundary forces that are transmitted into the plate interiors.

To summarize, small-scale paleostress/paleostrain indicators such as calcite twins allow to recognize large intraplate domains of first-order homogeneous paleostress orientations, somewhat similarly to regional-scale provinces of homogeneous contemporary stress orientations. This homogeneity likely reflects similar past and present-day first-order phenomena such as plate driving mechanisms and far-field stress transmission from plate boundaries into the far foreland. It thus comes that calcite twin data from plate interiors may provide a way to constrain past plate convergence trends and to evaluate the amount of coupling of the orogen with its foreland.

\subsection{Testing the Hypothesis of Coaxiality of Stress and Strain for Weak Deformation; a Combined Study Using CSIT and CSGT at Sheep Mountain Anticline (Wyoming, USA); Comparison with Anisotropy of Magnetic Susceptibility}

Sheep Mountain Anticline is a basement-cored, asymmetric fold in front of the Rocky Mountains (Erslev, 1993) (Fig. 11). This fold formed during the Laramide orogeny under a NE-trending compression at the end of the Maastrichtian and during Paleocene times (e.g., Dickinson and Snyder, 1978; Dickinson et al., 1988).

This well-exposed fold is a good analogue of a fracturedfolded reservoir and has first given rise to microtectonic studies based on fracture analysis (e.g., Bellahsen et al., 2006a). In order to bridge the usual gap between macroscopic and microscopic stress/strain record, stress and strain orientations and magnitudes were investigated in Paleozoic and Mesozoic strata in both the forelimb and the backlimb using calcite twins (Amrouch et al., 2010a).

The samples analysed with the Groshong's CSGT reveal three stages of finite strain. NW-SE layer-parallel shortening is preserved, although tilted, by twinning in the backlimb and in the forelimb, with a small $\varepsilon_{\min }(\sim-1 \%)$. The related strain tensors are purely contractional with $\varepsilon_{\max }$ perpendicular to bedding. NE-SW -directed layer-parallel shortening is preserved in matrix from one sample which recorded a $\varepsilon_{\text {min }}$ equal to $-2 \%$ and a $\varepsilon_{\max }$ perpendicular to bedding and vertical (Fig. 11b). Three samples yield a strain tensor with $\varepsilon_{\min }$ perpendicular to the fold axis in the present-day attitude, suggesting that calcite twinning in these samples mainly recorded late stage fold tightening (Fig. 11b); $\varepsilon_{\min }$ values vary between $\sim-2$ and $3 \% ; \varepsilon_{\max }$ is horizontal and parallel to the fold axis.

The same samples and additional others were also analyzed in terms of stress using the CSIT (Amrouch et al., 2010a). Calcite twin analysis reveals three main tectonic stages: two stages of layer-parallel shortening (a pre-folding compression nearly parallel to the fold axis and a pre-folding compression perpendicular to the fold axis after bedding is restored to horizontal), and a stage of post-folding compression also trending normal to fold axis. Minor extensional stress tensors are also recognized in place.

The first layer-parallel shortening stage, mainly preserved in the rock matrix from both limbs, corresponds to a strikeslip stress regime with $\mathrm{N} 135^{\circ}$-directed compression. The second 

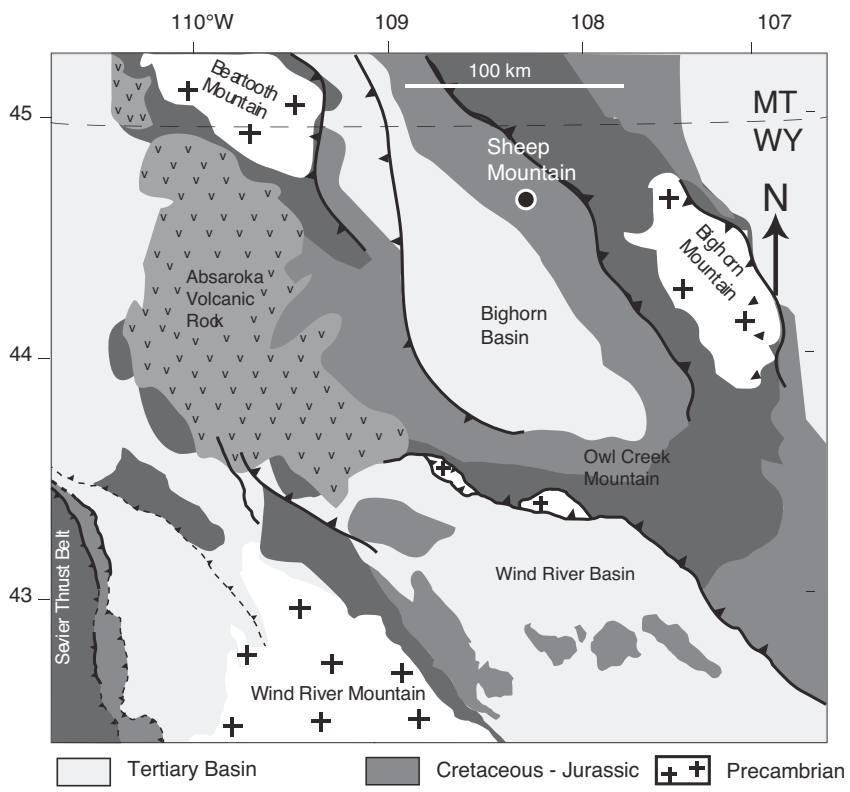

a)
\begin{tabular}{|l|l|l}
\hline $\mathrm{v}$ & Tertiary Volcanic Rocks \\
\end{tabular}
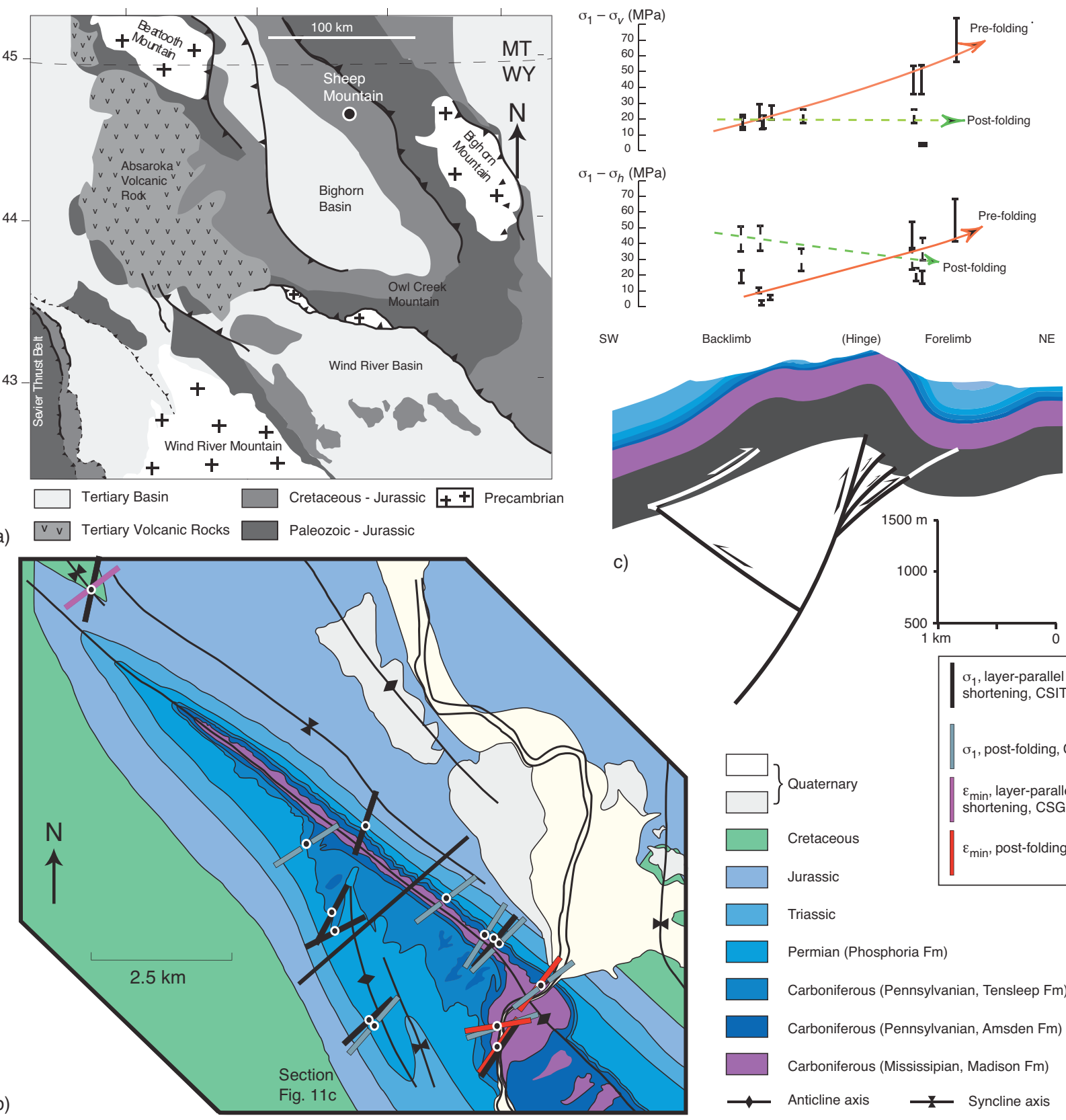

o $\sigma_{1}$, layer-parallel $\sigma_{1}$, post-folding, CSIT

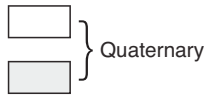

$\varepsilon_{\text {min }}$, layer-parallel shortening, CSGT

$\varepsilon_{\text {min }}$, post-folding, CSGT Jurassic Triassic

Permian (Phosphoria Fm)

Carboniferous (Pennsylvanian, Tensleep Fm)

Carboniferous (Pennsylvanian, Amsden Fm)

Carboniferous (Mississipian, Madison Fm)

$\longrightarrow$ Anticline axis $\quad \longrightarrow$ Syncline axis

Figure 11

a) Simplified geological map of Laramide uplifts in Wyoming (USA). b) Geological map of the NW part of Sheep Mountain Anticline and paleo- stress/strain orientations related to the Laramide layer-parallel shortening and late stage fold tightening derived from calcite twins. c) Evolution of Laramide pre- and late/post-folding differential stresses through Sheep Mountain Anticline (sites projected perpendicularly on the cross section)(modified after Amrouch et al., 2010a).

layer-parallel shortening stage corresponds to the NE-SW direction of compression with a maximum principal stress axis $\sigma_{1}$ that trends perpendicular to the fold axis (Fig. 1lb). The stress tensors were mainly obtained from veins in both limbs. Most samples recorded a compressional stress regime; only few of them yielded a strike-slip stress regime with a $\sigma_{3}$ axis horizontal and perpendicular to the veins from which twin measurements were taken.

A post-folding compressional stage is also preserved by twinning in veins and rock matrix, whatever the orientations 
of the veins from which measurements were taken. In all tensors the stress regime is strike-slip in type and the $\sigma_{1}$ axis strikes perpendicular to the fold axis (Fig. 11b).

This study constitutes the first attempt to use jointly Etchecopar's CSIT and Groshong's CSGT to derive both stress and calcite strain during folding from a single set of samples. The weak calcite twinning strain $(<3 \%)$ allows a direct comparison between finite strain tensors and stress tensors. In terms of orientations of shortening $\varepsilon_{\text {min }} /$ compression $\sigma_{1}$, the results show a very good consistency, for the two layer-parallel shortening stages and the late stage fold tightening, therefore supporting that internal strain of folded strata remained mainly coaxial (Fig. 11b). The stress regimes and the regime of deformation for the pre- and post-folding NESW compression are consistent (mainly purely compressional for layer-parallel shortening and of strike-slip type with $\varepsilon_{\max } / \sigma_{3}$ nearly horizontal for late stage fold tightening). However, for the NW-SE directed compression, the regime is dominantly strike-slip in term of stress and dominantly compressional in terms of strain.

The Laramide stress/strain orientations and regimes derived from calcite twins are in good agreement with those derived from fault slip data and fracture analysis (Bellahsen et al., 2006a; Amrouch et al., 2010a). This study demonstrates that stresses were consistently recorded from the scale of the grain/aggregate to the scale of the fold limb, thus allowing reliable extrapolation of local stress reconstructions (as for instance from oriented cores) to the whole fold structure and valuable description of the main lines of its stress/strain evolution.

As in Taiwan (Sect. 3.3.1), this study emphasizes that twinning occurs mainly before or during the onset of folding as layer-parallel shortening passively tilted during fold amplification (here layer-parallel shortening is polyphase, Sevier then Laramide) and after or at the latest stage of fold development (late stage fold tightening), with poor or no evidence for syn-folding twinning strain. These results are again in agreement with the results of Harris and van der Pluijm (1998) that show that twinning fabrics in the Hudson valley fold-thrust belt fall are related to prefolding layer-parallel shortening strain and to post-folding superimposed homogeneous strain, with no evidence of syn-folding twinning strain. The way strain is accommodated during folding therefore deserves discussion. At Sheep Mountain, joints and veins that do strike parallel to the trend of the anticline accommodated bending stresses at the hinge where high curvature occurs (Bellahsen et al., 2006; Amrouch et al., 2010a), while bedding-parallel slip mostly accommodated shortening oblique to bedding in the fold limbs. In the forelimb, bedding-parallel slip is clearly supported by slickenlines along bedding surfaces tail cracks emanating from bedding surfaces and polished bedding surfaces. In the backlimb, macroscopic evidence for bedding-parallel slip are much poorer, but the study of the anisotropy of magnetic susceptibility (Amrouch et al., 2010b) in the carbonates reveals there a magnetic foliation oblique to the bedding plane which is inconsistent with standard layer-parallel shortening fabrics but supports bedparallel shearing.

Amrouch et al. (2010b) also conducted a microstructural analysis based on the anisotropy of rock physical properties (anisotropy of magnetic susceptibility and anisotropy of $P$-wave velocity) in carbonates and interbedded sandstones and on Fry strain analysis in sandstones at sheep Mountain. The results demonstrate a very good agreement between the principal axes of the anisotropy of physical properties of rocks, Fry strain axes and principal stress/strain axes derived from calcite twinning. They further show a good consistency of the strain ellipsoid orientation with macroscopic fracturing and with the overall anticline geometry. The other main result of this study is that the structural contrast between the forelimb and the backlimb of the anticline shown by differential stress values (Fig. 11c; see Sect. 5.3.1) and macroscopic distribution of fractures (Bellahsen et al., 2006a; Amrouch et $a l ., 2010 \mathrm{a})$ is also revealed by the petrophysical characteristics of cored samples. This asymmetry is likely related to the way the fold developed above a basement thrust fault (Fig. 11c). The analyses of the anisotropy of physical properties of sedimentary rocks, of Fry strain, of calcite twins and of fracture data combined with petrographic and diagenetic observations can therefore be reliably used to unravel the strain history of folded strata, and to characterize the deformation mechanisms active at various scales during fold evolution.

Some authors tried to make a direct comparison between calcite twinning and the anisotropy of magnetic susceptibility in carbonates. These authors noticed a rough parallelism between the axis of maximum susceptibility $K_{\max }$ in the samples and the applied maximum principal stress $\sigma_{1}$; this parallelism could be explained by the fact that the optical axis, which is the axis of the maximum susceptibility of the calcite crystals, is rotated by twinning towards the direction of compression (Fig. 2a) (Schmid et al., 1987). According to Amrouch (2010), this explanation holds in the case of sparitic calcite but probably not really for micrite, since twinning very hardly occurs in small sized calcite crystals. Therefore, if anisotropy of magnetic susceptibility is measured from micritic calcite matrix, the recorded anisotropy is likely carried either by the intersection of the pressure-solution cleavage plane with the bedding or by the intersection of the joints/veins with the bedding. The microstructural analysis at Sheep Mountain anticline shows that pressure-solution cleavages and joints developed consistently with folding, which provides an explanation for the consistency observed between the tensors of anisotropy of the physical properties and those of the paleostress and strain obtained by calcite twin analysis (Amrouch, 2010). 


\section{CALCITE TWINS AS INDICATORS OF PALEOSTRESS MAGNITUDES}

The study of absolute stress magnitudes in the crust is an important topic in Earth sciences, but to date our knowledge of the actual stress level sustained by the continental crust remains poor. Data on contemporary stress magnitudes in the crust are few, and inferring paleostress magnitudes from the development of natural geological structures is inherently difficult (Lacombe, 2007). The poor knowledge we have on the paleostress levels sustained by natural rocks is partially linked to the fact that the paleopiezometric techniques do not share the same limitations, each of them having particular conditions of application (e.g., Newmann, 1994); this leads to multiple sources of methodological uncertainties which are superimposed to variability of natural phenomena.

Paleopiezometry basically relies upon establishing a close relationship between the state of stress and the development of a conspicuous element in the rock itself and calibrating it experimentally. Twinning of minerals depends on the magnitude of the shear stress which has been applied to them. It has been proposed to make use of this property for evaluating the stresses which have been supported by a rock during its history (e.g., Tullis, 1980).

As explained hereinafter, twinning in calcite occurs at low temperature and requires a low critical resolved shear stress of about $10 \pm 4 \mathrm{MPa}$ that depends on grain size (e.g., Rowe and Rutter, 1990; Lacombe and Laurent, 1996) and internal twinning strain (e.g., Turner et al., 1954; Laurent et al., 2000; Lacombe, 2001). Calcite twinning is not sensitive to either strain rate or confining pressure, and therefore fulfils most of the requirements for paleopiezometry. Calcite twins have consequently been used for a long time as a paleopiezometer (Jamison and Spang, 1976; Laurent, 1984; Rowe and Rutter, 1990; Lacombe and Laurent, 1992).

\subsection{How to Quantify Differential Stress and Principal Stress Magnitudes?}

\subsubsection{Summary of the Principles of Previous Estimates of Differential Stress Magnitudes Based on the Techniques of Jamison and Spang (1976) and Rowe and Rutter (1990)}

The basis of the widely used method of Jamison and Spang (1976) is that in a sample without any preferred crystallographic orientation, the relative percentages of grains twinned on $0,1,2$ or 3 twin plane(s) depend on the applied $\left(\sigma_{1}-\sigma_{3}\right)$ value. Since this relationship has been experimentally calibrated, knowing these relative percentages in a sample, and under the hypothesis of a constant critical shear stress value for twinning, the order of magnitude of $\left(\sigma_{1}-\sigma_{3}\right)$ can be estimated. Among the major limitations of this method is that it does not take into account the grain size dependence of twinning, does not check the mutual compatibility of measured twin systems and relies upon the hypothesis of uniaxial stress. In addition, the method does not allow to relate the differential stress estimates to a given stress regime since principal stress orientations are not determined. These limitations cast some doubt on the significance of derived bulk differential stress values in case of polyphase tectonics.

The method of Rowe and Rutter (1990) is based on the sensitivity of the twinning incidence (\% of grains in a given size range containing optically visible twins), twin volume fraction (\% of the volume of the twin fraction of the grain) and twin density (number of twins per $\mathrm{mm}$ ) to differential stresses; in turn, estimates of these parameters are used to infer differential stress magnitudes. The first two criteria are found to be largely dependent on grain size, since twinning is easier in large grains. The twin density (number of twins per $\mathrm{mm}$ ) is poorly grain-size dependent. The use of this last criterion provides reasonable results of $\left(\sigma_{1}-\sigma_{3}\right)$ when applied at high temperature, but leads to overestimates of differential stresses when applied at a low-temperature twinning deformation (see discussion in Ferrill, 1998). As a result, the Rowe and Rutter paleopiezometer best applies to twinning deformation at high temperatures (between $200^{\circ} \mathrm{C}$ and $800^{\circ} \mathrm{C}$ ), and at large strains (7-30\%), and is not appropriate for evaluating differential stress magnitudes from calcite twinning analysis in outer parts of orogens. In addition, this method shares the same limitation than the Jamison and Spang technique in not checking the mutual consistency of twin sets from which differential stress values are derived and not allowing to relate differential stress estimates to given stress orientations.

\subsubsection{Assumption of a Constant Critical Resolved Shear Stress for Twinning}

Differential stress estimates using the CSIT are based on a constant critical resolved shear stress $\tau_{a}$ for twinning. This assumption is also shared by the technique of Jamison and Spang (1976). Using the latter technique, a constant critical resolved shear stress of $10 \mathrm{MPa}$ is generally adopted (e.g., Craddock et al., 1993; Craddock and van der Pluijm, 1999; Gonzales-Casado and Garcia-Cuevas, 1999). Based on the analysis of experimentally deformed samples, Lacombe and Laurent (1996) and Laurent et al. (2000) have not only demonstrated the reliability of the CSIT, but also emphasized that the critical resolved shear stress is sensitive to strain hardening. Although some authors consider that a constant yield stress value for twinning is unlikely (De Bresser et al., 1997), Lacombe and Laurent (1996) and Laurent et al. (2000) results suggest that the critical resolved shear stress for twinning can be considered constant for samples displaying a nearly homogeneous grain size. For samples displaying a mean grain size of $\sim 200-300 \mu \mathrm{m}$ and deformed between $0^{\circ} \mathrm{C}$ and $100^{\circ} \mathrm{C}$ at $2-2.5 \%$ strain, it equals $10 \mathrm{MPa}$; for the same samples deformed at nearly $1-1.5 \%$ strain, the critical 
resolved shear stress rather equals $5 \mathrm{MPa}$ (Laurent et al., 2000; Lacombe, 2001: Fig. 12a). For samples displaying different grain sizes, a grain size- critical resolved shear stress relationship has been tentatively proposed by Rocher et al . (2004); it is currently being improved. To compare, the critical resolved shear stress required for twinning to occur in dolomite is much higher than in calcite (Wenk et al., 1983), about $100 \mathrm{MPa}$ (Tullis, 1980), which precludes occurrence of dolomite mechanical twinning at low stress levels.

\subsubsection{Determination of Differential Stress Magnitudes}

The four parameters defining the reduced stress tensor T' (orientation of principal stress axes and $\Phi$ ratio) being derived from inversion of calcite twin data, quantifying the deviatoric stress tensor $\mathrm{T}_{\mathrm{D}}$ defined as:

$$
\mathrm{T}_{\mathrm{D}}=\mathrm{T}-\left[\left(\sigma_{1}+\sigma_{2}+\sigma_{3}\right) / 3\right] \mathbf{I}
$$

requires the determination of a fifth parameter of the complete stress tensor: the scalar $k\left(=\sigma_{1}-\sigma_{3}\right)$. This determination relies on the existence of a constant critical resolved shear stress for twinning $\tau_{a}$ and on the accurate estimate of $\tau_{a}$, that corresponds to the normalized value of the critical resolved shear stress for the reduced stress tensor used for calculation.

Under the assumption of a constant critical resolved shear stress for twinning $\tau$, the differential stress magnitudes can be determined as follows (Etchecopar, 1984; Lacombe and Laurent, 1996; Laurent et al., 2000): $\left(\sigma_{1}-\sigma_{3}\right)=\tau_{a} / \tau_{a}$, and $\left(\sigma_{2}-\sigma_{3}\right)=\Phi\left(\sigma_{1}-\sigma_{3}\right)$, where $\tau_{a}$, is the smallest resolved shear stress applied on the twinned planes accounted for by the stress tensor and therefore the normalized value of the critical resolved shear stress when $\left(\sigma_{1}-\sigma_{3}\right)$ is scaled to 1 .

As for other techniques of paleostress estimation based on calcite twin analysis (e.g., Jamison and Spang, 1976; Rowe and Rutter, 1990), the paleopiezometric technique used herein yields the maximum differential stress $\left(\sigma_{1}-\sigma_{3}\right)$ related to a given palaeostress orientation, because the differential stresses are computed by taking into account the maximum percentage of twinned planes consistent with the tensor and therefore the smallest $\tau_{a}$, value. In the absence of recrystallization, the meaning of such differential stress estimates is therefore that of the peak stresses sustained by rocks during a given episode of their tectonic history.

As for calculation of principal stress orientations, uncertainties on differential stress values can be evaluated by inverting calcite twin data from experimentally deformed samples and comparing the computed differential stress values with the differential stress values applied during the experiments. This is made first by defining the best tensor solution (e.g., Laurent et al., 2000) and second by comparing the differential stress values related to this best solution to the differential stress values applied during the experiments. The effect of the order of sorting of successive stress tensors on computed differential stress values when the samples are polyphase has also been evaluated (Rocher, 1999). Although the interval of confidence may sometimes be as large as $50 \%$ (Laurent et al., 2000), uncertainties are generally about $\pm 20 \%$, including the uncertainty on the actual value of critical resolved shear stress for twinning which is strain hardening and grain size dependant.

In the field, in order to prevent bias due for instance to local record of stress concentrations, which may lead to overestimated stresses which may be not representative of the far-field stress of interest, several samples are usually collected for a given locality and the weighted mean of the differential stress values is generally retained as the most reliable estimate.

\subsubsection{Quantifying Absolute Stress Magnitudes}

Knowing the deviatoric stress tensor, a single parameter is missing in defining the complete stress tensor. This sixth parameter corresponds to the isotropic component of the tensor that cannot be determined using calcite twinning only since twinning does not depend on isotropic stress. In order to assess the actual magnitudes of $\sigma_{1}, \sigma_{2}$ and $\sigma_{3}$, it is thus necessary to fix directly one of them, or at least to determine a third additional relationship between them.

The method to determine the complete stress tensor relies upon combination of analyses of calcite twins and rock mechanics data (Lacombe and Laurent, 1992; Lacombe, 2001). For a given tectonic event and a given site, it consists of finding the values of $\sigma_{1}, \sigma_{2}$, and $\sigma_{3}$ required for consistency between newly formed faulting, frictional sliding along preexisting planes, and calcite twinning (Fig. 12b).

The differential stress value $\left(\sigma_{1}-\sigma_{3}\right)$ and the $\Phi$ ratio determined from calcite twins fix the scale (i.e., the diameter) of the Mohr circles associated with the tensor. To completely describe the stress regime (orientation and magnitude), the isotropic component of the tensor is missing. The determination of this parameter, which corresponds to the position of the Mohr circles along the normal stress axis in the Mohr diagram, can be done in various ways (Fig. 12b).

Failure: If subsets of newly formed faults and twins provide similar reduced stress tensors in a given site, it can be reasonably inferred that they formed during the same tectonic event, and therefore they may be thought to have developed "contemporaneously" in terms of geologic time. As calcite twins record the "peak" stress reached during the entire history of the rock mass, the maximum recorded differential stress should correspond to the stress which induced rock failure, because fresh failure releases stress. Consequently, if new faults developed, fitting the $\left(\sigma_{3}, \sigma_{1}\right)$ Mohr circle determined from calcite twins with the intrinsic failure (or crack development) curve yields values of principal stresses that prevailed just before rupture (see also Fig. 7d).

Friction: Because all points that represent reactivated preexisting planes should lie above the friction curve (Byerlee, 1978) in the Mohr diagram, fitting the $\left(\sigma_{3}, \sigma_{1}\right)$ Mohr circle determined from calcite twins with the friction line, so that 


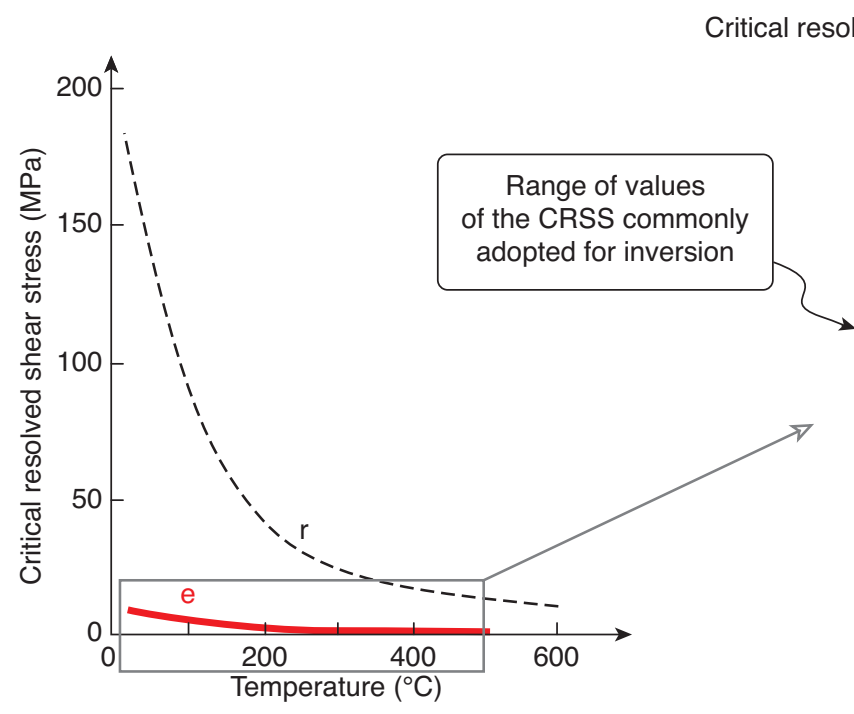

a)

b)

Figure 12

a) Critical shear stress values for calcite twinning as a function of temperature and strain inferred from laboratory experiments. Modified after De Bresser et al. (1997), Laurent et al. (2000) and Lacombe (2001). b) Principle of determination of principal stress magnitudes based on combination of inversion of calcite twin data, fault slip data, paleodepth estimate and rock mechanics. Modified and completed after Lacombe and Laurent (1992). inherited faults are located above the friction line, allows determination of the principal stress values. This requirement imposes a constraint on the position of the Mohr circle along the normal stress axis and yields principal stress magnitudes.

Evaluation of the vertical principal stress: Most paleostress reconstructions based on calcite twins (and fault slip data: e.g., Lisle et al., 2006) yield a highly plunging principal stress axis, close to vertical (within the usual $10-15^{\circ}$ range of uncertainties), provided that passively rotated stress axes due to folding are interpreted after backtilting to their prefolding attitude. The verticality of one principal stress is also indicated by widespread joints in foreland environments which are very close to vertical, a condition that is most likely if one of the principal stresses is vertical (Engelder and Geiser, 1980). Considering a vertical principal stress is also 
common in most in situ measurements of contemporary stresses (Zoback et al.. 1989; Zoback, 1992; Brudy et al., 1997). Cornet (1993) however points out that the vertical direction is not a principal direction in the vicinity of the ground surface in mountainous area or, more generally, anywhere the ground surface is not horizontal. The question then arises of determining the depth up to which this nonverticality of one of the principal stresses may be observed.

As discussed by Lacombe (2007), paleostress reconstructions deal with stresses associated with tectonic deformation of rocks at depth, hence generally of larger magnitudes and of longer duration (the duration of a "geological tectonic event") than "snapshots" of ambient stresses provided by insitu measurements (Lacombe, 2007). These paleostresses are consequently "averaged" over several millions years, so they are controlled to the first order by the vertical (gravity) and the horizontal (tectonic forces) directions and do not reflect local and/or temporal sources of stress perturbation as for instance the evolving-with-time topography can be. As a result, it is generally correct to equal the magnitude of the vertical principal stress to the overburden load, $\left(\rho g z-P_{f}\right.$.) where $\rho$ is the average density of the overburden. $g$ is the acceleration of gravity, $z$ is the depth, and $P_{f}$ is the fluid pressure. Paleodepth of overburden can be evaluated using stratigraphic data in favourable settings. The actual pore fluid pressure at the time of deformation (and the porosity as well) being unfortunately often out of reach, hydrostatic conditions are usually adopted as the most realistic conditions of fluid pressure.

As the inversion of calcite twin data provides directly differential stress magnitudes, the determination of the principal stress magnitudes only requires one piece of information among the above criteria. If the failure or the friction criterion is available, the magnitude of the vertical principal stress is fixed (Fig. 12b). If the burial thickness is unknown, this estimate of the value of the (effective) vertical stress can be used to estimate the weight of overburden, and therefore the depth at the time of deformation. This estimate can be compared with stratigraphic information (if available) to check for consistency.

A different method to estimate paleoburial and subsequent erosion/vertical uplift by folding from calcite twins in foldthrust belts is presented in Section 6 .

\subsection{Paleo-differential Stress Magnitudes from Calcite Twins and Evolution of Structural Permeability in Minor Faults from Stable Forelands: Example from the Causses Basin, France}

Fluid paleotransfers are related to fault activity to a large extent. Paleofluid pathways in an argillaceous formation may be related to the hydraulic behavior of faults and vein networks and therefore to the stress states arising inside the fractures. These states of stress can be evaluated from the analysis of the twinning of calcite filling the veins and the mineralized cores of faults. Constantin et al. (2007) have analysed the relationship between deformation and so-called fluid paleotransfers in minor faults in an argillaceous formation located in the Causses Basin (France). They attempted at estimating paleo-differential stress magnitudes under which the fault activity may have occurred and consequently, the change in the structural fault permeability, using the CSIT. The analysed faults, created and active during the same tectonic event, were found permeable (both the damage zone and the core zone) under a mean $\left(\sigma_{1}-\sigma_{3}\right)$ value of 40-50 MPa. Lower values were also obtained, indicating probably variations of the frictional strength. The paleofluid flows inside the damage zone have occurred for $\left(\sigma_{1}-\sigma_{3}\right)$ values lower than 40-50 MPa even though the core zone remained impermeable. On the other hand, the reactivation of the fractures during a second tectonic event implies mean $\left(\sigma_{1}-\sigma_{3}\right)$ values higher than 40-50 MPa, especially for the faults that are badly oriented with respect to the principal tectonic stress directions. The core zone of these faults remained sealed and impermeable or became permeable by development of microcracks inside the pre-existing fillings. These higher levels of differential stresses and the difference of mechanical behavior of the pre-existing fractures are linked to the fracture orientation with respect to the stress field and the structural content (heritage) of the fracture volume.

\subsection{Calcite Twins as Indicators of Paleostress Magnitudes in Fold Structures}

\subsubsection{Differential Stress Magnitudes in the Chunglun Anticline and SW Taiwan Anticlines: Burial Depth vs Tectonic Style}

Coming back to paleostress reconstructions in Central Taiwan (Fig. 6, 7; Sect. 3.3.1), $\left(\sigma_{1}-\sigma_{3}\right)$ magnitudes reported by Lacombe (2001) for pre-folding type I tensors range from 85 to $210 \mathrm{MPa}$, with a weighted average value of $145 \mathrm{MPa}$; for post-folding type II tensors, $\left(\sigma_{1}-\sigma_{3}\right)$ magnitudes range from 54 to $76 \mathrm{MPa}$ with a mean value of $65 \mathrm{MPa}$; for the type III (syn-folding?) $\left(\sigma_{1}-\sigma_{3}\right)$ magnitudes range from 52 to $85 \mathrm{MPa}$ with a weighted mean value of $70 \mathrm{MPa}$. The nearly similar small range of differential stress values obtained for syn-folding (type III) and the postfolding tensors (stage II) suggests nearly homogeneous stress conditions since the late stages of folding; in contrast, the prefolding differential stress magnitudes show a large range of values. This large range can be interpreted as reflecting rapid changes in depth of overburden due to early synfolding exhumation and subsequent rapid changes in differential stress magnitudes.

It comes that the first stage of layer-parallel shortening twinning strain occurs (type I tensors) under an average NW-SE compression at high levels of differential stresses (Fig. 7c, d). The travel along the ramp and the related transport 
(second stage) is associated with shortening oblique to bedding; fold development caused rapid uplift and subsequent erosion, leading to both rapid decreasing lithostatic load and differential stresses. Finally, because of locking of the thrust (third stage), the whole system is homogeneously shortened, and late twinning occurs (type II tensors) under lower stress levels (Fig. 7c, d).

In SW Taiwan (Kaohsiung), the average differential stress value $\left(\sigma_{1}-\sigma_{3}\right)$ related to the NW-SE compression is about $60 \mathrm{MPa}$, while that related to the late ENE-WSW to E-W compression is about $26 \mathrm{MPa}$. The differential stress value $\left(\sigma_{1}-\sigma_{3}\right)$ corresponding to the NW-SE compression obtained at Fengshan is $23 \mathrm{MPa}$. At the Kenting locality in the Hengchun peninsula, differential stress values are about 33 MPa value for the NW-SE compression and $24 \mathrm{MPa}$ value for the E-W compression (Lacombe, 2001).

At Chukou locality the decrease of differential stress values inferred from the comparison between prefolding and postfolding stages is probably due to the decreasing weight of overburden during synfolding erosion (Fig. $7 \mathrm{c}$-e). The difference between the average differential stress value estimated for the postfolding stage at Chukou locality $(\sim 70 \mathrm{MPa})$ and that obtained in the Kaohsiung area (60 MPa) for the NW-SE compression could also be related to a different paleodepth of deformation. However, the same NW-SE compression is associated in the Hengchun peninsula with a mean value of differential stresses of $30 \mathrm{MPa}$ much lower than in the Kaohsiung area: this difference cannot be accounted for only by the slight difference in paleodepth of deformation, and therefore suggests a southward decrease in stress magnitudes (Fig. 6).

The difference in stress magnitudes accompanying folding between Central and southern Taiwan could partly lie in the contrast of deformation styles between the two regions (Fig. 6 and 7a). Actual collision occurs in the Chukou area and pre-Miocene formations (including the crystalline basement?) are involved in the deformation of frontal areas (Mouthereau et al., 2001, 2002); in contrast, the southwestern province, made of thick poorly consolidated muddy Quaternary deposits, is the onland extension of the Manilla accretionary wedge; it deforms mainly above a low-dipping shallow decollement surface, regularly spaced faultpropagation folds and pop-up structures indicating lowfriction conditions (Lacombe et al., 1997, 1999). It therefore comes that structural domains where the basement is involved in shortening and where superimposed shallow and deep decollement tectonics occur (e.g., Chukou area in Central Taiwan, Fig. 7a2) can be associated with highfriction conditions which may lead to tectonic records of high stress levels in the rocks before folding occurred, in contrast of thin-skinned domains deformed above a low-friction decollement (e.g., SW Taiwan, Fig. 7a3).

Finally, as suggested in Section 3.2, fitting the $\left(\sigma_{3}, \sigma_{1}\right)$ Mohr circles to the experimental failure envelope allows to estimate principal stress values for prefolding and syn-folding/post-folding states of stress, respectively (Fig. 7d: Lacombe et al., 1996a; Lacombe, 2001). Equating the magnitude of the calculated vertical stress with the effective weight of overburden yields estimates of pre- and postfolding cover thicknesses and provides a way to evaluate the amount of syn-folding erosion during the Pleistocene NW-SE compression (Fig. 7e).

\subsubsection{Differential Stress Magnitudes in Sheep Mountain Anticline: Signature of Stress Perturbations by Underlying Basement Thrust and Differential Stress Relaxation Between Fold Limbs}

In addition to the reconstruction of paleostress/strain trends, differential stress magnitudes were investigated in both the forelimb and the backlimb of Sheep Mountain anticline (Sect.4.3) to unravel the history of stress sustained by folded strata.

During Laramide layer-parallel shortening, both $\left(\sigma_{1}-\sigma_{v}\right)$ and $\left(\sigma_{1}-\sigma_{h}\right)$ increased from the backlimb toward the fore$\operatorname{limb}\left(\sigma_{v}\right.$ is the vertical principal stress, and $\sigma_{h}$ the minimum horizontal principal stress). During Laramide late stage fold tightening, $\left(\sigma_{1}-\sigma_{v}\right)$ remains nearly constant in the backlimb and the forelimb, while $\left(\sigma_{1}-\sigma_{h}\right)$ decreases from the backlimb to the forelimb (Amrouch et al., 2010a: Fig. 11c).

The increase toward the forelimb of Laramide layer-parallel shortening-related differential stresses can be convincingly modelled through a simple numerical model of stress perturbations induced in the overlying cover at the tip of the underlying basement thrust as suggested by Bellahsen et al. (2006b): $\left(\sigma_{1}-\sigma_{3}\right)$ and $\left(\sigma_{1}-\sigma_{2}\right)$ magnitudes increase when approaching the fault tip and reach a maximum above the fault tip (Amrouch et al., 2010a). With the assumption that the backlimb of Sheep Mountain anticline is located in the hanging-wall of the basement thrust fault and that the forelimb is located within its footwall, this simple model accounts for the first-order increase of differential stresses derived from calcite twins within the folded cover (Fig. 11c). On the other hand, the decrease of $\left(\sigma_{1}-\sigma_{h}\right)$ from the backlimb to the forelimb during late stage fold tightening can be explained by differential relaxation of stresses (Amrouch et al., 2010a).

A tentative scenario of evolution of principal stress magnitudes in the fold has been further proposed based on construction of Mohr diagrams, thus providing for the first time an integrated picture of stress distribution related to folding above a basement thrust fault.

\subsection{Calcite Twins as Indicators of Paleostress Magnitudes in Thrust Belts: Differential Stress Magnitudes in the Zagros Buckled Cover}

Calcite twin analysis in the Zagros belt (Fig. 8b) reveals that to a first approximation, peak differential stresses related to the $025^{\circ}$ compression in the Zagros belt (Sect. 3.3.2) are low 
and nearly constant across the Simply Folded Belt and the Southern Iranian Plateau (Fig. 8d). Except for one sample adjacent to the High Zagros Fault, most values lie within a narrow range of $40 \mathrm{MPa} \pm 15 \mathrm{MPa}$ (Fig. $8 d$ : Lacombe et al., 2007). The relative homogeneity of differential stresses agrees with the homogeneously distributed shortening across the Simply Folded Belt, where no deformation gradient toward the backstop is observed in contrast to classical foldthrust wedges. This supports buckling of the cover sequence over the weak Hormuz salt as the dominant regional mechanism of deformation (Mouthereau et al., 2006, 2007a, b).

These differential stress estimates noticeably differ from previously reported stress values in fold belts, which are much higher (e.g., 90-150 MPa in the Idaho-Wyoming belt: Craddock and Van der Pluijm, 1999), and show a strong decay across both the fold belt and the undeformed foreland (e.g., 100 to $20 \mathrm{MPa}$ in the Sevier-Appalachian forelands: Van der Pluijm et al., 1997).

\subsection{Calcite Twins as Indicators of Paleostress Magnitudes in Stable Forelands: Intraplate Differential Stress Magnitudes Away from Sevier, Appalachian and Pyrenean Past Convergent Plate Boundaries}

To a first order the orientations of the present-day stresses are known and interpreted within the framework of plate kinematics (World Stress Map, Zoback et al., 1989; Heidbach et al., 2008, 2010); in several plates the maximum horizontal stress is subparallel to the direction of absolute plate motion, suggesting that the forces driving the plates also dominate the stress distribution into the plate interior (see Sect.4.2). In contrast, a large unknown is the stress level within plates. The way stresses are transmitted away from plate boundaries is also poorly known, as well as the actual control of the coupling between the orogen and its foreland in convergence settings on this transmission and the role of crustal rheology on intraplate stress attenuation. Available data are few, and numerical models only provide partial answers to these questions in terms of orders of magnitudes; disagreements between models and their sensitivity to assumptions made on lithospheric rheology show that new data are required, at different scales.

In continental plates, in situ stress measurements, macrostructures and small stress/strain markers demonstrate the far field transmission of orogenic stresses (see Sect. 3.5 and 4.2). Such a transmission requires that the lithosphere is sufficiently rigid to play the role of a stress guide, but at the same time accommodation of displacements induced by these far-field stresses far away at the front of the orogen (e.g., Ziegler et al., 1998) requires partial decoupling within the lithosphere, expectedly within the ductile lower crust. A way to reconcile both aspects could be to consider that the channel guiding stresses related to lithospheric plate motion is mainly the brittle upper crust and that the upper crust can be partially decoupled from the deeper lithospheric levels (e.g., Lacombe and Mouthereau, 2002).

Stress versus depth relationships and strength of the upper crust under hydrostatic fluid pressure (Zoback and Townend, 2001) suggest that the assumption that the brittle upper crust is able to sustain and therefore to transmit a large part of the stresses related to plate motion is realistic. However, the way stress magnitudes evolve away from convergent plate boundaries is generally out of reach and poorly documented by available contemporary stress data.

The way stress magnitudes evolve away from past convergent plate boundaries can be studied using paleopiezometers such as calcite twinning. One however has to keep in mind that the determination of deviatoric stress tensors using thin $e$-twin lamellae in calcite covers only a range of low temperature domain (typically, they are defined in the 0-5 kilometers of the elastic upper crust), so the extrapolation to the lithospheric scale should be considered with caution.

Calcite twinning studies have documented decreasing magnitudes of orogenic differential stresses within the foreland of various orogens worldwide with increasing distance to the front (Craddock et al., 1993; Lacombe et al., 1996b; Van der Pluijm et al., 1997). Differential stresses decrease from 100-80 MPa close to the orogenic front to $10-20 \mathrm{MPa}$ in the far foreland up to $2500 \mathrm{~km}$ from the Sevier and Appalachian-Ouachita orogenic fronts (Craddock et al., 1993; Van der Pluijm et al., 1997; Craddock and Van der Pluijm, 1999) (Fig. 13a, b). Errors on reported differential stress magnitudes are within $20 \%$ (Sect. 5.1.3) according to the authors themselves. For Craddock et al. (1993) and Van der Pluijm et al. (1997), the decay of orogenic stresses across the foreland is exponential and independent on the geodynamic setting and on the style and age of the orogen.

Examining closely the data, one can notice that Craddock et al. (1993) reported some $\left(\sigma_{1}-\sigma_{3}\right)$ values lower than $20 \mathrm{MPa}$, which seems unconsistent with the critical resolved shear stress value for twinning of $10 \mathrm{MPa}$ adopted since the resolved shear stress exerted on the best oriented twin plane is $\left(\sigma_{1}-\sigma_{3}\right) / 2$, so $\left(\sigma_{1}-\sigma_{3}\right)$ should at least equal two times the critical resolved shear stress to cause twinning. In addition, because no information about the depth at which paleo- differential stresses were evaluated is available, there is no way to normalize each individual stress datum by the depth at which twin deformation occurred, so this fall-off may well be an artifact of the different depths at which paleostresses were determined. It is clear from their results that differential stress magnitudes of $80-100 \mathrm{MPa}$ are unrealistic at or close to the surface in the foreland. Taking into account an average stress/depth gradient of $23-25 \mathrm{MPa} / \mathrm{km}$ (e.g., Lacombe, 2007), the 80-100 MPa magnitude close to the front corresponds to a probable depth of 3-4 km, while the 20-30 MPa minimum should have prevailed at a depth of $\sim 1 \mathrm{~km}$. However, the decay of differential stresses is considered 


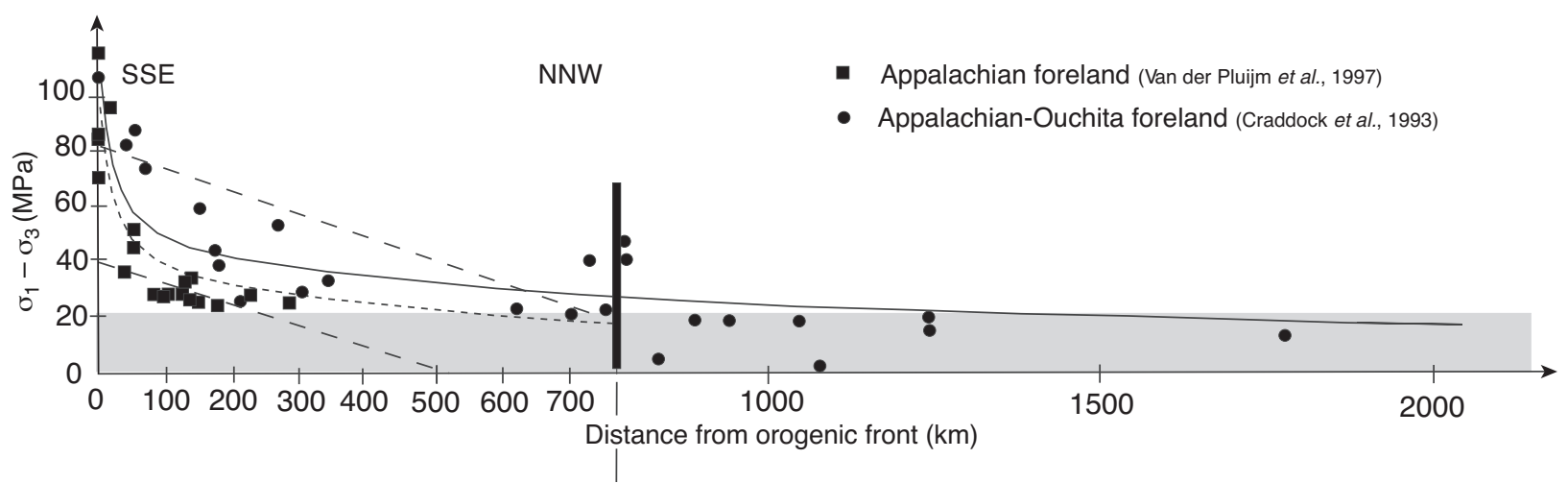

a)

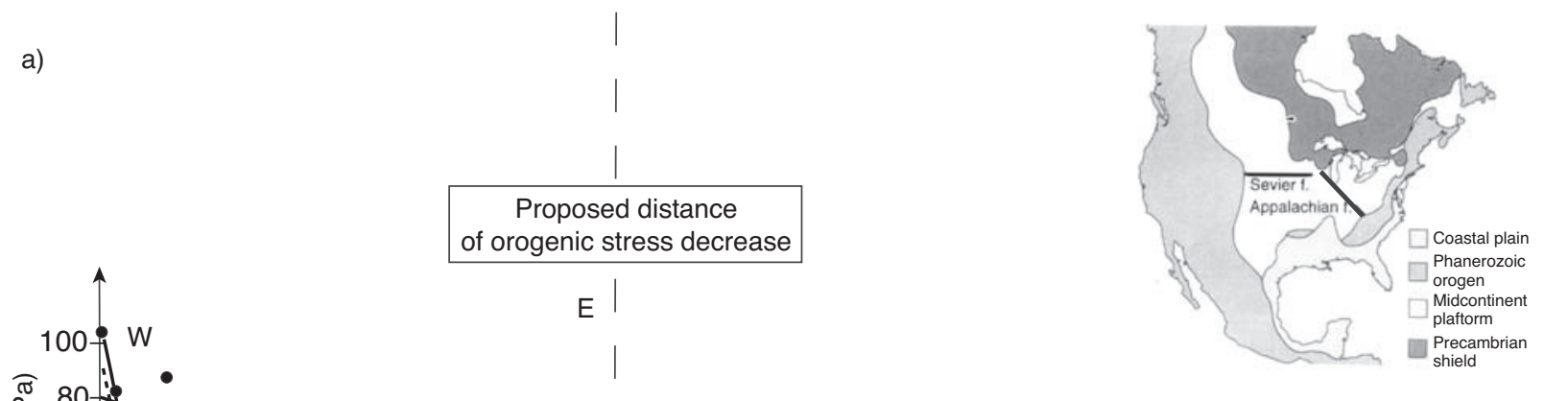

b)

of orogenic stress decrease

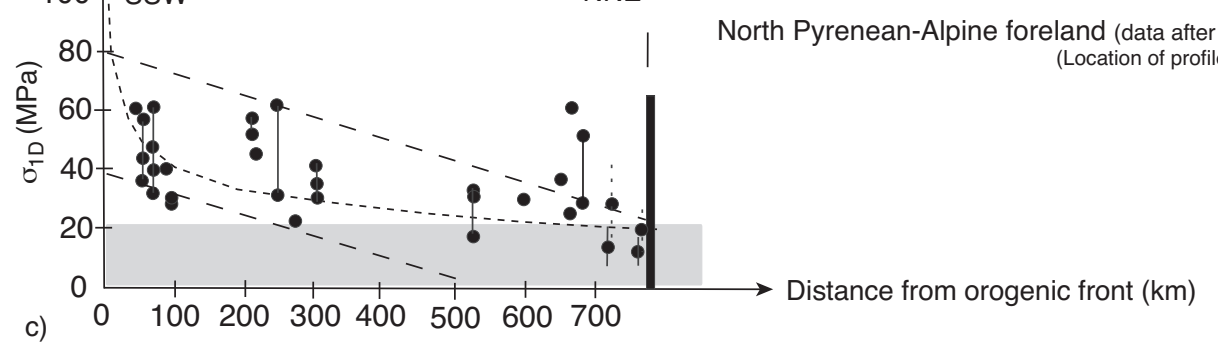

Figure 13

a) Decreasing $\left(\sigma_{1}-\sigma_{3}\right)$ magnitudes in the Appalachian-Ouachita forelands. b) Decreasing $\left(\sigma_{1}-\sigma_{3}\right)$ magnitudes in the Sevier foreland. c) Decreasing magnitude of the deviatoric component of $\sigma_{1}$ related to the Pyrenean compression in the North Pyrenean foreland. The continuous curves in A and B show the exponential decrease of stress magnitudes in the orogenic stable forelands as reported by the authors. If one considers that the fall-off of stress magnitudes is significant only within the $700 \mathrm{~km}$ interval from the front, the dashed curves define a possible (nearly) exponential trend of decrease of stress magnitudes in this interval, while the range between the linear dashed lines defines a possible linear trend of decrease of stress magnitudes in the same interval, until an intraplate stress background value of $20 \mathrm{MPa}$ is reached (grey colored domain). Note that the $20 \mathrm{MPa}$ value also corresponds to the minimum differential stress required for calcite twinning to occur assuming a critical shear stress value of $10 \mathrm{MPa}$ (see text). 
within the so-called undeformed foreland away from the deformation front; so one can reasonably infer that because no significant orogen-related deformation and therefore no large lateral variations of erosion and exhumation have occurred in the foreland, rocks presently at the surface and from which measurements are taken were likely deformed at nearly similar depths (within a $\sim 2 \mathrm{~km}$ range) and that the fall-off of differential stresses may be, at least partly, significant.

In order to prevent bias due to comparison of differential stresses collected at different depths, Lacombe et al. (1996b) rather considered the deviatoric component of $\sigma_{1}, \sigma_{1 \mathrm{D}}$ (Fig. 13c). Their results were completed by recent estimates of stress magnitudes in eastern France (Lorraine platform) and in the Isle of Wight by Rocher et al. (2004). Although $\sigma_{1 \mathrm{D}}$ is different from $\left(\sigma_{1}-\sigma_{3}\right)$, a decrease of $\sigma_{1 \mathrm{D}}$ values with increasing distance to the front is similarly observed, especially within the 700-800 km interval from the front. In more detail, stress data show that the decay reaches the constant minimum 20-30 MPa stress level at $\sim 700 \mathrm{~km}$ from the front, so at larger distances, the stress level rather reflects the expected background intraplate stress level of several tens of MPa (e.g., Solomon et al., 1980).

Although the homogeneity of stress orientations effectively suggests transmission of tectonic stresses farther away (Fig. 9), uncertainties of $20 \%$ on magnitudes and in a minor part uncertainties on the depth of deformation suggest that the decay is significant only within the $700 \mathrm{~km}$ interval from the front. Lacombe et al. (1996b) have suggested that this apparent exponential decay may be due to rapidly attenuated orogenic stresses superimposed onto a background level of intraplate stresses of 20-30 MPa. However, the dispersion of the available $\sigma_{1 \mathrm{D}}$ and $\left(\sigma_{1}-\sigma_{3}\right)$ values seems to date too large to unambiguously discriminate between linear versus exponential decay.

These results differ from those of Rocher et al. (2005) who examined calcite twin data in the foreland of the western Alps, along a SE-NW section from the Jura Mountains to the Isle of Wight. The Mio-Pliocene Alpine orogenic stress field varies in terms of stress regime, directions and values. The horizontal principal stress trends E-W in southern France, WNW in the center, and NW in the North, which can be attributed to the Alpine indenter phenomenon. The tectonic stress regime roughly corresponds to a pure compression in the Jura and rapidly evolves to the NW to a strike-slip state of stress, then beyond the Paris basin's centre to a perpendicular extension. Rocher et al. (2005) demonstrate that unlike the Pyrenean or Appalachian foreland stresses, the Alpine differential stresses do not significantly decrease from the Jura front to the far field (30 to $25 \mathrm{MPa}$ ), but instead show large wavelength variations: stress values are low in the Burgundy high, fractured and uprising during this tectonic event, and high in the center of the Paris basin centre, poorly fractured and subsiding during this event. Three tentative explanations have been proposed to account for these large- scale variations of alpine differential stresses in the cover: variation in crust thickness, crustal buckling during the Mio-Pliocene, and role of pre-existing fractures.

It is worthwhile noting that the absence of orogen-related large deformation (except close to few, favorably oriented preexisting weakness zones) in the far foreland indicates that far-field orogenic differential stresses presumably did not reach the stress limits related to frictional faulting equilibrium (i.e., stresses associated with frictional reactivation of pre-existing well-oriented crustal faults in the sense of Townend and Zoback, 2000). However, because calcite twinning is a paleopiezometer more sensitive to stress than faulting, it has the potential to allow derivation of lateral differential stress variations in the foreland and potential identification of stress "attenuation" with increasing distance from the convergent plate boundary that cannot be accounted for by differing depths of deformation. To this respect, the works by Craddock et al. (1993) and Van der Pluijm et al. (1997) support that crustal stresses are not always at the frictional yield in plate interiors. If the decreasing trend in differential magnitudes away from the deformation front does occur and has a geological meaning in terms of stress attenuation as stated by the authors, it indicates that lateral stress gradients may occur in the upper crust. A similar conclusion can be drawn based on occurrence of lateral gradients of differential stress magnitudes identified in Sheep Mountain Anticline (Sect. 5.3.2) and in Taiwan (Sect. 5.3.1). Interestingly, only ductile flow mechanisms (viscous-plastic creep mechanisms such as pressure-solution or calcite twinning), characteristic of the upper-tier of the ductile flow regime (Engelder, 1993) are able to permit such stress gradients below the frictional stress limit.

\section{CALCITE TWINS AS A TOOL FOR PALEOBURIAL ESTIMATES IN THRUST BELTS: EXAMPLE FROM THE OUTER ALBANIDES}

Vertical movements such as subsidence and tectonic uplift are key factors of the evolution of the fold-thrust belt-foreland basin system. While flexural subsidence and sedimentation prevail in the foreland basin, erosion is a dominant feature in the foothills domains, and this process controls to a large extent the paleoburial and the thermal evolution of rocks involved in folding. These parameters are of key importance for the understanding of the petrophysic evolution of (potential source) rocks, past vertical motions and hydrocarbon perspectives (e.g., Roure et al., 2010). Although the use of well logs, Bottom Hole Temperature and paleo-thermometers such as vitrinite reflectance $\left(R_{o}\right)$ and $T_{\max }$ is usually sufficient to calibrate the heat flow and geothermal gradients in the foreland, where limited erosion occurred, it is usually not possible to derive an univocal solution for paleo-burial and paleo-thermal gradient estimates in the foothills, if for instance based solely on maturity ranks of the organic matter. 
Alternate independent methods are then required to decrease the error bars in paleo-burial estimates, and to secure more realistic predictions of hydrocarbon generation. Apatite Fission Tracks analyses can provide access to absolute ages for the crossing of the $120^{\circ} \mathrm{C}$ isotherm and timing of the unroofing, whereas hydrocarbon-bearing fluid inclusions, when developing contemporaneously with aqueous inclusions, can provide a direct access to the pore fluid pressure and temperature of cemented fractures or reservoir at the time of cementation and hydrocarbon trapping (e.g., Roure et al., 2005).

A new method to estimate paleoburial and subsequent uplift by folding in fold-thrust belts, based on calcite twin analysis, has recently been proposed (Lacombe et al., 2009). This method basically combines estimates of differential stresses related to layer-parallel shortening with the hypothesis that stress in the upper continental crust is in frictional equilibrium (Zoback and Townend, 2000), a situation that is probably common (see discussion in Lacombe, 2007). Assumption is made that layer-parallel shortening is recorded coevally and more or less homogeneously in a strata without any relation to the structural position of the samples after folding, e.g., there is no underlying basement fault inducing local stress perturbations in the cover during layer-parallel shortening as stated in the basement-cored Sheep Mountain Anticline (Sect. 5.3.2). Because layer-parallel shortening reflects the onset of stress build-up in horizontal strata just before or at the onset of folding, related differential stresses are likely recorded at the maximum burial, just before subsequent uplift. Paleodepth values inferred from differential stresses related to layer-parallel shortening therefore yield an upper bound for burial and constrain the amount of subsequent exhumation / vertical movement. Paleoburial estimates from post-folding stress tensors place additional constraints on the depth at which rocks were when folding ended, and, therefore, on the exhumation path of these rocks toward the surface. Note that this approach is fundamentally different from that of estimating the paleodepth of deformation by combining calcite twin analysis and rock mechanics data (Lacombe and Laurent, 1992) (Sect. 5.1.4).

Lacombe et al. (2009) used this new approach to determine the palaeoburial of Cretaceous limestones that are presently involved in folding at the front of the southern Outer Albanides (Velaj et al., 1999; Robertson and Shallo, 2000; Nieuwland et al., 2001; Meço and Aliaj, 2000; Fig. 14). The Albanian foothills formed during the Alpine orogeny as a consequence of the deformation of the former eastern passive margin of Apulia; the external zones were overthrust during the Neogene (Nieuwland et al., 2001; Roure et al., 2004).

Calcite twin analysis provides constraints on the early stages of the tectonic history of the Albanian foreland thrust belt, including the successive stages of development of prefolding vein systems currently observed in folded strata and related fluid flows (Lacombe et al., 2009; Vilasi et al., 2009). Two main regional vein systems have been identified in the Saranda and Kremenara anticlines (Fig. 14a). The first set likely predated folding and developed during burial in response to the flexure of the foreland in front of the advancing thrust sheets, possibly under high fluid pressures. The second set is a vein system formed in response to the regional compressional stress responsible for folding; this compression is oriented ENE-WSW and is clearly recorded by calcite twinning from these vein sets (Fig. 14b).

Lacombe (2007) has shown that paleo-differential stress against depth suggests a trend of increasing differential stresses with depth, supporting that stress in the upper crust is mostly at frictional equilibrium (Townend and Zoback, 2000). For given stress and pore pressure regimes, and knowing the differential stress values from calcite twin analysis, one can make use of this relationship to estimate the paleodepth of deformation. Figure $14 \mathrm{c}$ reports the curves of differential stress values as a function of depth in a crust in frictional equilibrium, for strike-slip (SS) and reverse faulting (C) stress regimes, values of $\lambda\left[\lambda=P_{f} / \rho g z\right.$, where $P_{f}$ is the pore fluid pressure, $\rho$ the density of the overlying rocks, $g$ the acceleration of gravity and $z$ the depth] of 0.38 (hydrostatic) and 0 (dry) and for values of the friction coefficient $\mu$ of 0.6 and 0.9 .

Reporting the differential stress values corresponding to reverse, strike-slip or mixed reverse/strike-slip (i.e., with low $\Phi$ ratio) stress regimes related to the regional compression on the above-mentioned curves yields the probable range of depths at which Cretaceous limestones recorded twinning strain. In Saranda, the depth range of the investigated samples just before the onset of folding (i.e., at the maximum burial) was about $1.5-5.5 \mathrm{~km}$, around a mean value of $4 \pm$ $1 \mathrm{~km}$ that represents the most likely burial depth of these limestones (Fig. 14c).

These paleodepth estimates were compared to, and were found consistent to a first-order with, other independent paleoburial indicators, such as thickness of sedimentary formations in the Ionian zone, thermal modelling of the thickness of eroded rock in holes and paleotemperatures derived from microthermometry of paleofluids, as well as maturity rank of the organic matter in the Mesozoic series sampled in surface outcrops of the Ionian Basin and Kruja Zone (see discussion in Lacombe et al., 2009).

A major interest of this method is that it can potentially be carried out anywhere twinned calcite occurs. It only requires that stress orientations and differential stress magnitudes related to layer-parallel shortening be unambiguously determined, even where the tectonic evolution is polyphase, which is to date allowed by the CSIT. In the absence of other paleodepth indicators, and provided that the assumption of crustal frictional stress equilibrium is valid (see discussion in Lacombe, 2007), applying this new method in fold-thrust belts will provide valuable constraints on the amount of 


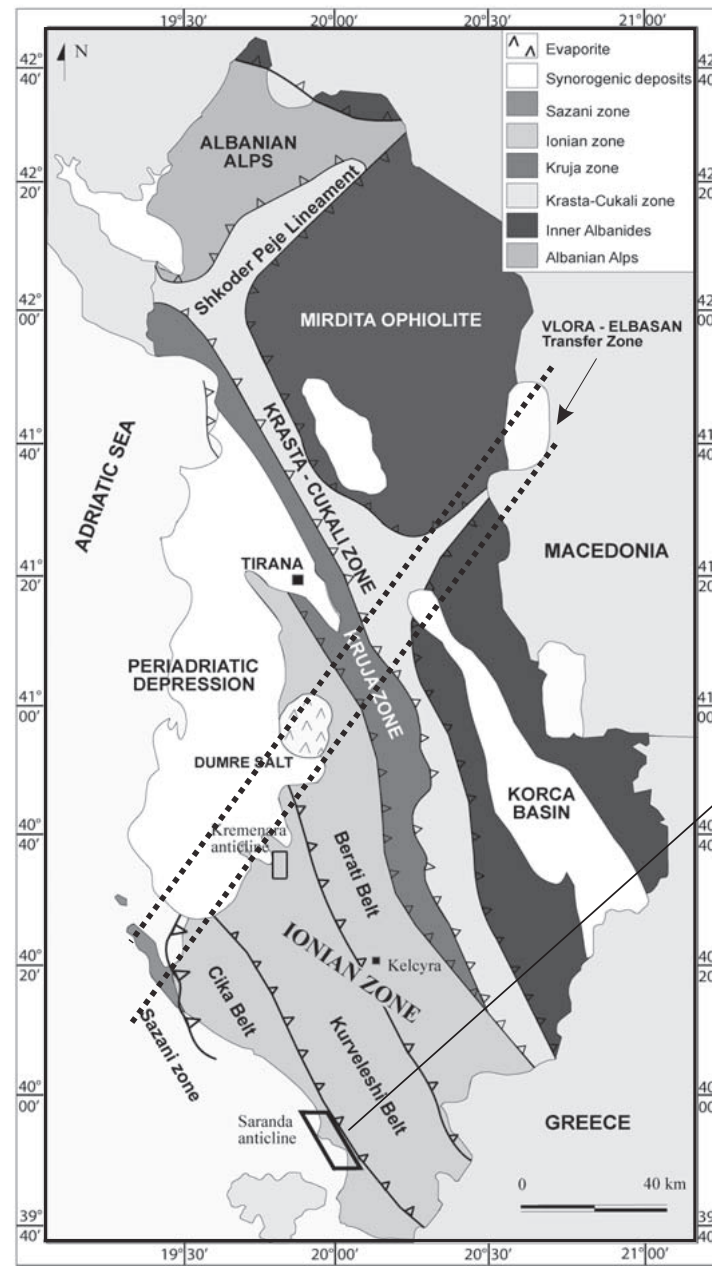

a)

Figure 14

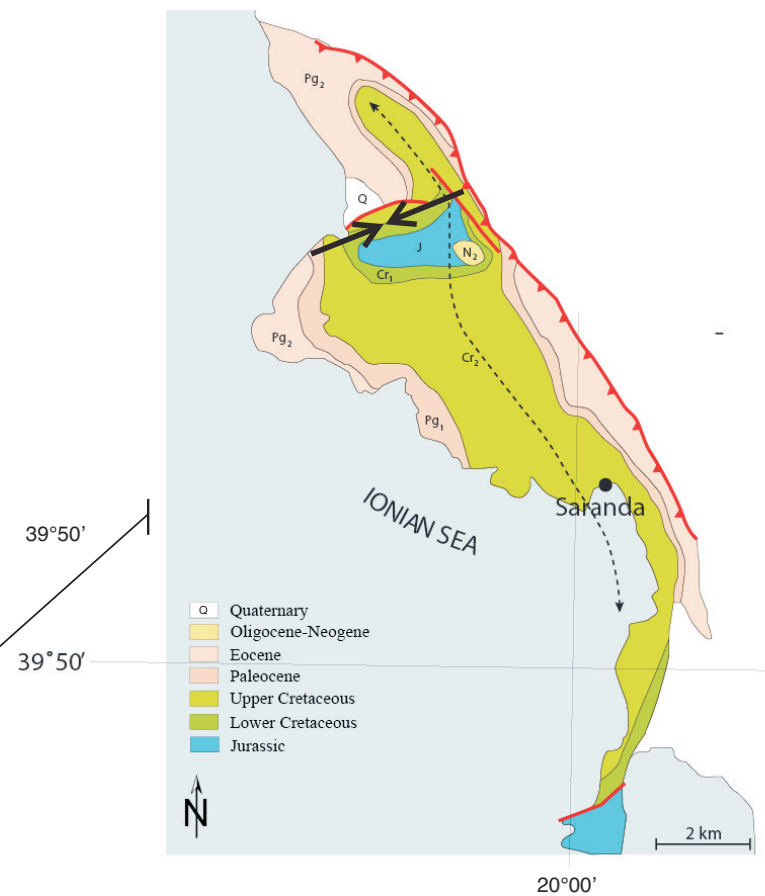

b)

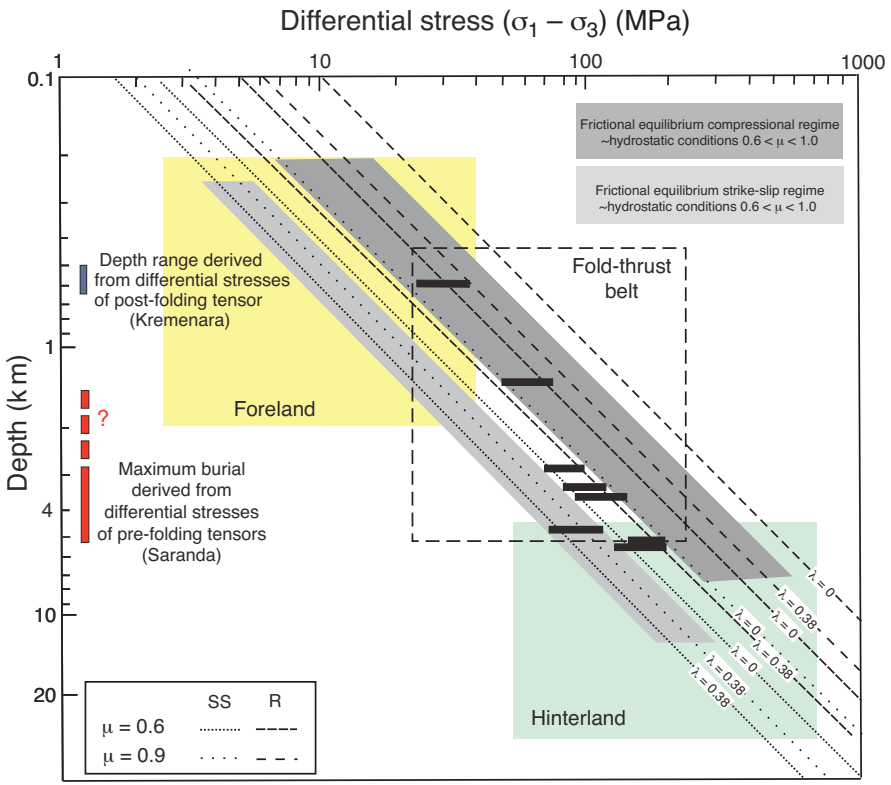

c)

a) Structural map of the Albanides. b) Detailed map of the Saranda anticline. The thin dashed line corresponds to the anticline axis. The black convergent arrows indicate the mean compressional trend derived from calcite twinning in samples collected along a section across the fold (Lacombe et al., 2009). c) Differential stress values determined from calcite twins reported on stress/depth curves built for a crust in frictional stress equilibrium (Lacombe, 2007), and derived paleoburial values for pre- and post-folding stress tensors corresponding to the ENE compressional trend. Dashed lines illustrate stress-depth relationships predicted using Coulomb frictional-failure theory for coefficients of friction $\mu$ of 0.6 and 0.9 , pore pressures of $0(\lambda=0)$ and hydrostatic $(\lambda=0.38)$ and various tectonic regimes (SS: Strike-slip, R: Reverse) (modified after Lacombe et al., 2009). 
maximum burial of foreland rocks during flexural subsidence and of their subsequent uplift during folding, thus leading to a better quantification of vertical movements in forelands.

\section{CONCLUSION}

Among the minerals that have been used to constrain paleostress/strain orientations and to evaluate shear stress magnitudes based on the study of mechanical twins, calcite is the most common in carbonate sedimentary rocks. Because twinning in calcite occurs at low pressure and temperature and under relatively low stress levels, it is the most informative mineral to derive paleostress/strain in the upper crust. In contrast, twinning in dolomite, the other most common mineral in carbonate rocks, occurs at higher temperature and requires a higher critical resolved shear stress, which precludes any use of this mineral as a paleopiezometer in the upper crustal levels.

This paper provides a review of various aspects of the use of calcite twins in tectonic studies of orogenic forelands. Despite inherent limitations of the various techniques used in such analysis, calcite twins reveal to be a powerful tool to reliably reconstruct the successive stress and strain orientations and to constrain the structural style and kinematic history from surface samples or from cores from wells. To this respect, a major interest of calcite twin analysis is that it requires only a small piece of rocks of few $\mathrm{cm}^{3}$. Because of that, the technique is perfectly appropriate for determining paleostress/paleostrain from oriented cores from drill holes, where the poor number of observable microfaults usually precludes any reliable conclusion on the stress/strain field at depth. In addition, recent development point toward the use of calcite twin analysis to estimate differential and principal stress magnitudes, paleotemperature of deformation, and possibly paleoburial, and even to discuss the rheological behavior of the upper crust.

Although some points requires further investigations in the future, such as the effect of $\mathrm{Fe}, \mathrm{Mg}$ calcite content (e.g., Larson and Christy, 2008), or the actual value of the critical resolved shear stress for calcite that remains also to be better calibrated, especially as a function of grain size, the CSIT is to date the most efficient and powerful technique for calcite twin analysis in non-metamorphosed fold-thrust belts and "so-called" stable forelands.

\section{ACKNOWLEDGMENTS}

The author would like to thank the three anonymous reviewers, as well as the editor, François Roure, for their careful and insightful comments on the manuscript.

\section{REFERENCES}

Amrouch K., Lacombe O., Bellahsen N., Daniel J.M., Callot J.P. (2010a) Stress/strain patterns, kinematics and deformation mechanisms in a basement-cored anticline: Sheep Mountain anticline (Wyoming, USA), Tectonics 29, TC 1005.

Amrouch K., Robion P., Callot J.-P., Lacombe O., Daniel J.-M., Bellahsen N., Faure J.L. (2010b) Constraints on deformation mechanisms during folding provided by rock physical properties: A case study at Sheep Mountain anticline (Wyoming, USA), Geophys. J. Int. 182, 1105-1123.

Amrouch K. (2010) Apport de l'analyse microstructurale à la compréhension des mécanismes de plissement. Exemples de structures plissées aux USA (Wyoming) et en Iran (Zagros), Thèse, Université Pierre et Marie Curie - Paris 6, 2010-03, 477 p.

Barber D.J., Wenk H.R. (1976) Defects in deformed calcite and carbonate rocks, in Electron Microscopy in Mineralogy, H.R. Wenk (ed.), Springer Verlag, pp. 428-442.

Becker A. (2000) The Jura mountains: an active foreland fold-andthrust belt? Tectonophysics 321, 381-406.

Bellahsen N., Fiore P., Pollard D.D. (2006a) The role of fractures in the structural interpretation of Sheep Mountain Anticline, Wyoming, J. Struct. Geol. 28, 5, 850-867.

Bellahsen N., Fiore P., Pollard D.D. (2006b) From spatial variation of fracture patterns to fold kinematics: a geomechanical approach, Geophys. Res. Lett. 33, L02301.

Blanc E.J.P., Allen M.B., Inger S., Hassani H. (2003) Structural styles in the Zagros simple folded zone, Iran, Geol Soc. London J. 160, 401-412.

Burkhard M. (1993) Calcite twins, their geometry, appearance and significance as stress-strain markers and indicators of tectonic regime: a review, J. Struct. Geol. 15, 3-5, 351-368.

Brudy M. et al. (1997) Estimation of the complete stress tensor to $8 \mathrm{~km}$ depth in the KTB scientific drill holes: implications for crustal strength, J. Geophys. Res. 102, 18453-18475.

Byerlee J.D. (1978) Friction of rocks, Pure Appl. Geophys. 116, 615-626.

Colman-Sadd S. (1978) Fold development in Zagros simply folded belt, Southwest Iran, Am. Ass. Petrol. Geol. Bull. 62, 984-1003.

Constantin J., Laurent P., Vergély P., Cabrera J. (2007) Paleodeviatoric stress magnitudes from calcite twins and related structural permeability evolution in minor faults: Example from the toarcian shales of the French Causses Basin, Aveyron, France, Tectonophysics 429, 79-97.

Cornet F.H. (1993) Stresses in Rock and Rock Masses; Comprehensive Rock Engineering, Hudson (ed.), Pergamon Press Oxford, Vol. 3, Chap. 12, pp. 297-327.

Craddock J.P., Van der Pluijm B.A. (1989) Late Paleozoic deformation in the cratonic carbonate cover of eastern North America, Geology 17, 416-419.

Craddock J.P., Jackson M., Van Der Pluijm B., Versical R.T. (1993) Regional shortening fabrics in eastern north America: far-field stress transmission from the Appalachian-Ouachita orogenic belt, Tectonics 12, 1, 257-264.

Craddock J.P., Van Der Pluijm B. (1999) Sevier-Laramide deformation of the continental interior from calcite twinning analysis, westcentral North America, Tectonophysics 305, 275-286.

De Bresser J.H.P., Spiers C.J. (1997) Strength characteristics of the $r, f$ and $c$ slip systems in calcite, Tectonophysics 272, 1-23.

Dickinson W.R., Snyder W.S. (1978) Plate tectonics of the Laramide orogeny, Geol. Soc. Am. Memoir 151, 355-366. 
Dickinson W.R., Klute M.A., Hayes M.J., Janecke S.U., Lundin E.R., Mckittrick M.A., Olivares M.D. (1988) Paleogeographic and paleotectonic setting of laramide sedimentary basins in the central rocky-mountain region, Geol. Soc. Am. Bull. 100, 7, 1023-1039.

Engelder T. (1993) Stress regimes in the lithosphere, Princeton University Press, Princeton, N.J., 451 p.

Engelder T., Geiser P. (1980) On the use of regional joint sets as trajectories of paleostress fields during the development of the Appalachian plateau, N.Y.J. Geophys. Res. 85, 6319-6341.

Erslev E.A. (1993) Thrusts, back-thrusts and detachment of Rocky Mountain foreland arches, Schmidt C.J., Chase R.B., Erslev E.A. (eds), Laramide basement deformation in the Rocky Mountain foreland of the western United States, Geol. Soc. Am. Special Paper 280, 339-358.

Etchecopar A. (1984) Étude des états de contraintes en tectonique cassante et simulation de déformations plastiques (approche mathématique), Thèse de Doctorat-ès-Sciences, Univ. Sciences et Techniques du Languedoc, Montpellier, 270 p., unpublished.

Evans M.A., Dunne W.M. (1991) Strain factorization and partitioning in the North Mountain thrust sheet, central Appalachians, U.S.A., J.Struct. Geol. 13, 1, 21-35.

Ferrill D.A, Morris P., Evans M.A., Burkhard M., Groshong R.H., Onasch C.M. (2004) Calcite twin morphology: a low-temperature deformation geothermometer, J. Struct. Geol. 26, 8, 1521-1529.

Ferrill D.A., Groshong R.H. (1993) Kinematic model for the curvature of the northern Subalpine Chain, France, J. Struct. Geol. 15, 523-541.

Ferrill D.A. (1998) Critical re-evaluation of differential stress estimates from calcite twins in coarse-grained limestones, Tectonophysics $\mathbf{2 8 5}, \mathbf{7 7 - 8 6}$.

Ferrill D.A. (1991) Calcite twin widths and intensities as metamorphic indicators in natural low-temperature deformation of limestone, J. Struct. Geol. 13, 667-675.

Gagala L. (2009) Reliability of selected procedures of stress inversion and data separation for inhomogeneous populations of calcite twins and striated faults: insights from numerical experiments, Int. J. Earth Sci. (Geol. Rundsch) 98, 461-479.

Gong S.-Y., Lee T.-Y., Wu J.-C., Wang S.-W., Yang K.-M. (1996) Possible links between the development of Plio-Pleistocene coral reef limestones and thrust migration in southwestern Taiwan, J. Geol. Soc. China 39, 151-16.

Gonzales-Casado J.M., Garcia-Cuevas C. (1999) Calcite twins from microveins as indicators of deformation history, J. Struct. Geol. 21, 875-889.

Groshong R.H. Jr. (1972) Strain calculated from twinning in calcite, Geol. Soc. Am. Bull. 83, 2025-2038.

Groshong R.H. Jr. (1974) Experimental test of least-squares strain calculations using twinned calcite, Geol. Soc. Am. Bull. 85, 18551864.

Groshong R.H. Jr., Pfiffner O.A., Pringle L.R. (1984) Strain partitioning in the Helvetic thrust belt of Eastern Switzerland from the leading edge of the internal zone, J. Struct. Geol. 6, 5-18.

Harris J.H., Van der Pluijm B.A. (1998) Relative timing of calcite twinning strain and fold-thrust belt development: Hudson Valley fold-thrust belt, New York, USA, J. Struct. Geol. 20, 21-31.

Heidbach O., Tingay M., Barth A., Reinecker J., Kurfeß D., Müller B. (2008) The World Stress Map database release 2008, DOI: 10.1594/GFZ.WSM.Rel2008.

Heidbach O., Tingay M., Barth A., Reinecker J., Kurfeß D., Müller B. (2010) Global crustal stress pattern based on the World Stress Map database release 2008, Tectonophysics 482, 3-15.
Ho C.S. (1986) A synthesis of the geologic evolution of Taiwan, Tectonophysics 125, 1-16.

Holl J.E., Anastasio D.J. (1995) Cleavage development within a foreland fold and thrust belt, southern Pyrenees, Spain, J. Struct. Geol. 17, 357-369.

Hung J.-H. (1994) Analysis of deformation fabrics in the Sani thrust sheet and the Chuhuangkeng anticline of western Taiwan, Petrol. Geol. Taiwan 29, 105-126.

Hung J.-H., Kuo C.-K. (1999) Calcite twins for determining paleostrain and paleostress in the thrust front of the Taiwan collisional belt, J. Geol. Soc. China 42, 209-232.

Jamison W.R., Spang J. (1976) Use of calcite twin lamellae to infer differential stresses, Geol. Soc. Am. Bull. 87, 868-887.

Janssen C., Rybacki E., Dresen G. (2007) Critical re-evaluation of calcite twins as a low-temperature deformation geothermometer, Geophys. Res. Abstracts 9, 02228, SRef-ID: 1607-7962/gra/ EGU2007-A-02228.

Lacombe O. (1992) Maclage, fracturation et paléocontraintes intraplaques: application à la plate-forme carbonatée ouesteuropéenne, Thèse, Université Pierre et Marie Curie, Mém. Sciences de la Terre, $316 \mathrm{p}$.

Lacombe O. (2001) Paleostress magnitudes associated with development of mountain belts: insights from tectonic analyses of calcite twins in the Taiwan Foothills, Tectonics 20, 6, 834-849.

Lacombe O. (2007) Comparison of paleostress magnitudes from calcite twins with contemporary stress magnitudes and frictional sliding criteria in the continental crust: Mechanical implications, J. Struct. Geol. 29, 86-99.

Lacombe O., Amrouch K., Mouthereau F., Dissez L. (2007) Calcite twinning constraints on late Neogene stress patterns and deformation mechanisms in the active Zagros collision belt, Geology 35, 3, 263-266.

Lacombe O., Angelier J., Chen H.-W., Deffontaines B., Chu H.-T., Rocher M. (1997) Syndepositional tectonics and extension-compression relationships at the front of the Taiwan collision belt: a case study in the Pleistocene reefal limestones near Kaohsiung, SW Taiwan, Tectonophysics 274, 83-96.

Lacombe O., Angelier J., Laurent P. (1992) Determining paleostress orientations from faults and calcite twins: a case study near the Sainte-Victoire Range (southern France), Tectonophysics 201, 141-156.

Lacombe O., Angelier J., Laurent P. (1993) Calcite twins as markers of recent compressional events in an active orogen: The reefal limestones of southern Taiwan as a case study, C.R. Acad. Sci. II 316, 1805-1813.

Lacombe O., Angelier J., Laurent P., Bergerat F., Tourneret C. (1990) Joint analyses of calcite twins and fault slips as a key for deciphering polyphase tectonics: Burgundy as a case study, Tectonophysics 182, 279-300.

Lacombe O., Angelier J., Rocher M., Bergues J., Chu H.-T. Deffontaines B., Hu J.-C. (1996a) Contraintes et plissement au front d'une chaîne de collision: l'exemple des calcaires récifaux pliocènes de Yutengping (Taiwan) ,Bulletin de la Société Géologique de France 167, 361-374.

Lacombe O., Laurent P. (1992) Determination of principal stress magnitudes using calcite twins and rock mechanics data, Tectonophysics 202, 83-93.

Lacombe O., Laurent P. (1996) Determination of deviatoric stress tensors based on inversion of calcite twin data from experimentally deformed monophase samples: preliminary results, Tectonophysics 255, 189-202.

Lacombe O., Laurent P., Angelier J. (1994) Calcite twins as a key to paleostresses in sedimentary basins: Preliminary results from drill cores of the Paris basin, in Peri-Tethyan Platforms, Roure F. (ed.), Technip, Paris, pp. 197-210. 
Lacombe O., Laurent P., Rocher M. (1996b) Magnitude de la contrainte déviatorique pyrénéenne dans l'avant-pays nordpyrénéen, C.R. Acad. Sci. II 322, IIa, 229-235.

Lacombe O., Malandain J., Vilasi N., Amrouch K., Roure F. (2009) From paleostresses to paleoburial in fold-thrust belts: preliminary results from calcite twin analysis in the outer Albanides, Tectonophysics, Geology of the Vertical Movements of the Lithosphere 475, 128-141.

Lacombe O., Mouthereau F. (1999) Qu'est-ce que le front des orogènes ? L'exemple de l'orogène pyrénéen, C.R. Acad. Sci. II 329, II, 889-896.

Lacombe O., Mouthereau F. (2002) Basement-involved shortening and deep detachment tectonics in forelands of orogens: insights from recent collision belts (Taiwan, western Alps, Pyrenees), Tectonics 21, 4, 1030.

Lacombe O., Mouthereau F., Angelier J., Deffontaines B. (2001) Structural, geodetic and sismological evidence for tectonic escape in SW Taiwan, Tectonophysics 333, 323-345.

Lacombe O., Mouthereau F., Deffontaines B., Angelier J., Chu H.-T., Lee C.-T. (1999) Geometry and Quaternary kinematics of fold-and-thrust units of southwestern Taiwan, Tectonics 18, 6, 1198-1223.

Lacombe O., Mouthereau F., Kargar S., Meyer B. (2006) Late Cenozoic and modern stress fields in the western Fars (Iran): implications for the tectonic and kinematic evolution of Central Zagros, Tectonics 25, 1, TC1003.

Larson A.-K., Christy A.G. (2008) On twinning and microstructures in calcite and dolomite, Am. Mineralogist 93, 1, 103-113.

Larroque J.M., Laurent P. (1988) Evolution of the stress field pattern in the South of the Rhine graben from the Eocene to the present, Tectonophysics 148, 41-58.

Laurent P. (1984) Les macles de la calcite en tectonique: nouvelles méthodes dynamiques et premières applications, Thèse de Doctorat-ès-Sciences, Univ. Sciences et Techniques du Languedoc, Montpellier, $324 \mathrm{p}$.

Laurent P., Kern H., Lacombe O. (2000) Determination of deviatoric stress tensors based on inversion of calcite twin data from experimentally deformed monophase samples, part II, Uniaxial and triaxial stress experiments, Tectonophysics 327, 131-148.

Laurent P., Bernard P., Vasseur G., Etchecopar A. (1981) Stress tensor determination from the study of $e$-twins in calcite: A linear programming method, Tectonophysics 78, 651-660.

Laurent P., Tourneret C., Laborde O. (1990) Determining deviatoric stress tensors from calcite twins: Application to monophased synthetic and natural polycrystals, Tectonics $\mathbf{9}, 379-389$.

Letouzey J. (1986) Cenozoic paleo-stress pattern in the Alpine foreland and structural interpretation in a platform basin, Tectonophysics 132, 215-231.

Lin, C.-W., Lee Y.-B. (1997) Calcite twin analysis of the Tungho and Kangkou limestones in the Coastal Range, eastern Taiwan, $J$. Geol. Soc. China 40, 639-652.

Lisle R.J., Orife T.O., Arlegui L., Liesa C., Srivastava D.C. (2006) Favoured states of paleostress in the Earth's crust: evidence from fault slip data, J. Struct. Geol. 28, 1051-1066.

Meço S., Aliaj S. (2000) Geology of Albania, Gebrüder Borntraeger, Berlin, $246 \mathrm{p}$.

Mouthereau F., Deffontaines B., Lacombe O., Angelier J. (2002) Along-strike variations of the Taiwan belt front: Basement control on structural style, wedge geometry and kinematics, Byrne T.B., Liu C.-S. (eds), Geology and Geophysics of an Arc-Continent Collision, Taiwan, Republic of China, Boulder, Colorado, Geol. Soc. Am. Spec. Pap. 358, 3, 35-58.

Mouthereau, F., Lacombe O., Deffontaines B., Angelier J., Brusset S. (2001) Deformation history of the southwestern Taiwan foreland thrust belt: Insights from tectono-sedimentary analysis and balanced cross-sections, Tectonophysics 333, 293-322.

Mouthereau F., Lacombe O., Meyer B. (2006) The Zagros Folded Belt (Fars, Iran): constraints from topography and critical wedge modelling, Geophys. J. Int. 165, 336-356.

Mouthereau F., Tensi J., Bellahsen N., Lacombe O., Deboisgrollier T., Kargar S. (2007a) Tertiary sequence of deformation in a thinskinned/thick-skinned collision belt: the Zagros Folded Belt (Fars, Iran), Tectonics 26, 5, TC5006.

Mouthereau F., Lacombe O., Tensi J., Bellahsen N., Kargar S., Amrouch K. (2007b) Mechanical constraints on the development of the Zagros Folded Belt, in Thrust belts and foreland basins: from fold kinematics to hydrocarbon systems, Lacombe O., Lavé J., Vergés J., Roure F. (eds), Frontiers in Earth Sciences, SpringerVerlag, Chap. 13, pp. 247-266.

Nemcok M., Kovac D., Lisle R.J. (1999) A stress inversion procedure for polyphase calcite twin and fault/slip data sets, J. Struct. Geol. 21, 597-611.

Nieuwland D.A., Oudmayer B.C., Valbona U. (2001) The tectonic development of Albania: explanation and prediction of stuctural styles, Mar. Petrol. Geol. 18, 161-177.

Newmann J. (1994) The influence of grain size and grain size distribution on methods for estimating paleostresses from twinning in carbonates, J. Struct. Geol. 16, 1589-1601.

Onasch C.M. (1983) Dynamic analysis of rough cleavage in the Martisburg Formation, Maryland, J. Struct. Geol. 5, 73-82.

Pfiffner O.A., Burkhard M. (1987) Determination of paleo-stress axes orientations from fault, twin and earthquake data, Ann. Tectonicae 1, 48-57.

Robertson A., Shallo M. (2000) Mesozoic-Tertiary evolution of Albania in its regional Eastern mediterranean context, Tectonophysics 316, 197-254.

Rocher M. (1999) Déformations et paléocontraintes des avant-pays de chaînes de collision: les piedmonts occidentaux de Taiwan et le bassin Sud-Aquitain, Thèse, Univ. Pierre et Marie Curie, Paris, 409 p.

Rocher M., Cushing M., Lemeille F., Baize S. (2005) Stress induced by the Mio-Pliocene Alpine collision in northern France, Bulletin de la Société Géologique de France 176, 4, 319-328.

Rocher M., Cushing M., Lemeille F., Lozac'h Y., Angelier J. (2004) Intraplate paleostresses reconstructed with calcite twinning and faulting: improved method and application to the Lorraine platform area (eastern France), Tectonophysics 387, 1-21.

Rocher M., Lacombe O., Angelier J., Chen H.W. (1996) Mechanical twin sets in calcite as markers of recent collisional events in a fold-and-thrust belt: Evidence from the reefal limestones of southwestern Taiwan, Tectonics 15, 5, 984-996.

Rocher M., Lacombe O., Angelier J., Deffontaines B., Verdier F. (2000) Cenozoic folding and faulting in the North Pyrenean Foreland (Aquitaine Basin, France): insights from combined structural and paleostress analyses, J. Struct. Geol. 22, 5, 627-645.

Roure F., Nazaj S., Mushka K., Fili I., Cadet J.P., Bonneau M. (2004) Kinematic evolution and petroleum systems: an appraisal of the outer Albanides, McClay K.R. (ed.), Thrust Tectonics and Hydrocarbon Systems, 82. AAPG Memoir, pp. 474-493.

Roure F., Swennen R., Schneider F., Faure J.L., Ferket H., Guilhaumou N., Osadetz K., Robion Ph., Vandeginste V. (2005) Incidence of tectonics and natural fluid migration on reservoir evolution in foreland fold-and-thrust belts, Oil Gas Sci. Technol. - Rev. IFP Energies nouvelles 60, 67-106. 
Roure F., Andriessen P., Callot J.-P., Ferket H., Gonzalez E., Guilhaumou N., Hardebol N., Lacombe O., Malandain J., Mougin P., Muska K., Ortuno S., Sassi W., Swennen R., Vilasi N. (2010) The use of paleo-thermo-barometers and coupled thermal, fluid flow and pore fluid pressure modelling for hydrocarbon and reservoir prediction in fold-and-thrust belts, Geol. Soc. London, Spec. Publ., Hydrocarbons in Contractional Belts, in press.

Rowe K.J., Rutter E.H. (1990) Paleostress estimation using calcite twinning: experimental calibration and application to nature, $J$. Struct. Geol. 12, 1, 1-17.

Schmid S.M., Panozzo R., Bauer S. (1987) Simple shear experiments on calcite rocks: rheology and microfabric, J. Struct. Geol.9, $5 / 6,747-778$.

Shelley D. (1992) Calcite twinning and determination of paleostress orientations: three methods compared, Tectonophysics 206, 193-201.

Solomon S.C., Richardson R.M., Bergman E.A. (1980) Tectonic stress: models and magnitudes, J. Geophys. Res. 85, B11, 60866092.

Spang J.H. (1972) Numerical method for dynamic analysis of calcite twin lamellae, GSA Bull. 83, 2, 467-471.

Sperner B., Ratschbacher L. (1994) A Turbo Pascal program package for graphical presentation and stress analysis of calcite deformation, Z. Dt. Geol. Ges. 145, 414-423.

Spiers C.J. (1979) Fabric development in calcite polycrystals deformed at $400^{\circ} \mathrm{C}$, Bull. Mineral. 102, 282-289.

Spiers C.J., Wenk H.R. (1980) Evidence for slip on $r$ and $f$ in the positive sense in deformed calcite single crystals, EOS Trans. AGU 61, 1128.

Stocklin J. (1968) Structural history and tectonics of Iran; a review, Am. Ass. Petrol. Geologists B. 52, 1229-1258.

Talebian M., Jackson J.A. (2004) A reappraisal of earthquake focal mechanisms and active shortening in the Zagros mountains of Iran, Geophys. J.Int. 156, 506-526.

Teufel L.W. (1980) Strain analysis of experimental superposed deformation using calcite twin lamellae, Tectonophysics $\mathbf{6 5}$, 291-309.

Tourneret C., Laurent P. (1990) Paleostress orientations from calcite twins in the north Pyrenean foreland, determined by the Etchecopar inverse method, Tectonophysics 180, 287-302.

Townend J., Zoback M.D. (2000) How faulting keeps the crust strong, Geology 28, 5, 399-402.
Tullis T.E. (1980) The use of mechanical twinning in minerals as a measure of shear stress magnitudes, J. Geophys. Res. 85, 6263-6268.

Turner F.J. (1953) Nature and dynamic interpretation of deformation lamellae in calcite of three marbles, Am. J. Sci. 251, 276-298.

Turner F.J., Griggs D.T., Heard H.C. (1954) Experimental deformation of calcite crystals, Geol. Soc. Am. Bull. 65, 883-934.

Turner F.J., Heard H.C. (1965) Deformation in calcite crystals at different strain rates, Univ. Calif. Publ. Geol. Sci. 46,103-126.

Van der Pluijm B.A., Craddock J.P., Graham B.R., Harris J.H. (1997) Paleostress in cratonic north America: implications for deformation of continental interiors, Science 277, 796-796.

Velaj T., Davison I., Serjani A., Alsop I. (1999) Thrust tectonics and the role of evaporites in the Ionian Zone of the Albanides, $A A P G$ Bull. 83, 1408-1425.

Vernant P. et al. (2004) Present-day crustal deformation and plate kinematics in the Middle East constrained by GPS measurements in Iran and northern Oman, Geophys. J. Int. 157, 381-398.

Vilasi N., Malandain J., Barrier L., Amrouch K., Callot J.-P., Guilhaumou N., Lacombe O., Muska K., Roure F., Swennen R. (2009) From outcrop and petrographic studies to basin-scale fluid flow modelling: the use of the Albanian natural laboratory for carbonate reservoir characterization, Tectonophysics, TOPO-Europe: the Geoscience of Coupled Deep Earth-Surface Processes 474, 367-392.

Ziegler P.A., Van Wees J.D., Cloetingh S. (1998) Mechanical controls on collision - related compressional intraplate deformation, Tectonophysics 300, 103-129.

Zoback M.D., Townend J. (2001) Implications of hydrostatic pore pressures and high crustal strength for the deformation of intraplate lithosphere, Tectonophysics 336, 19-30.

Zoback M.L. (1992) First and second order patterns of stress in the lithosphere: The World Stress Map Project, J. Geophys. Res. 97, 11703-11728.

Zoback M.L. et al. (1989) Global patterns of tectonic stress, Nature 341, 291-298.

Final manuscript received in November 2009 Published online in October 2010 